\title{
Subsurface processes generated by bore-driven swash on coarse-grained beaches
}

\author{
K. Steenhauer, ${ }^{1}$ D. Pokrajac, ${ }^{1}$ T. O’Donoghue, ${ }^{1}$ and G. A. Kikkert ${ }^{2}$ \\ Received 9 November 2010; revised 7 January 2011; accepted 18 January 2011; published 15 April 2011.
}

[1] Large-scale laboratory experiments presented in this paper involved bore-driven swash on permeable immobile coarse-grained beaches. Two different sediments were used $\left(d_{50}=1.5\right.$ and $\left.8.5 \mathrm{~mm}\right)$ resulting in different beach permeability and surface roughness. The experiments yielded detailed measurements of swash depth and velocities, wetting front, pressure, and groundwater levels across the swash zone. This paper is focused on the processes occurring within the beach. The measurements provide the shape of the wetting front and the groundwater table and reveal the behavior of air in the unsaturated region of the beach. Air is initially at atmospheric pressure, but the pressure builds up when air becomes encapsulated between the saturated region formed below the swash and the groundwater table. For the $1.5 \mathrm{~mm}$ beach, entrapped air significantly affected the water exchange between the swash and the subsurface. The considerable buildup of interstitial air pressure reduced vertical hydraulic gradients and thus infiltration rates. At the lower end of the beach the hydraulic gradients even became negative, indicating flow reversal and exfiltration. In contrast, for the $8.5 \mathrm{~mm}$ beach the rate of infiltration was only slightly affected by the buildup of pore-air pressure. The vertical hydraulic gradients were more than twice the magnitude of those within the $1.5 \mathrm{~mm}$ beach. The results presented in the paper clarify the mechanisms that drive and impede the water exchange between the surface and subsurface flow. In particular, infiltration into the initially unsaturated part of the beach and the resulting air entrapment play a significant role in swash and similar flows.

Citation: Steenhauer, K., D. Pokrajac, T. O’Donoghue, and G. A. Kikkert (2011), Subsurface processes generated by bore-driven swash on coarse-grained beaches, J. Geophys. Res., 116, C04013, doi:10.1029/2010JC006789.

\section{Introduction}

[2] The swash zone is the region periodically submerged as waves run up and down the beach, linking the ocean and the coastal aquifer, and playing a significant role in crossshore and longshore sediment transport processes. The swash zone, considered to be the most dynamic region of the beach, is a complex system which is affected by several interrelated processes. In the past several decades our understanding and modeling of the bulk characteristics of swash zone hydrodynamics has progressed significantly. However, the smaller-scale processes are not yet well understood. A key issue is the exchange of water between the flow above and within the beach, which occurs via infiltration into the beach or exfiltration from it.

[3] Turner and Masselink [1998] were among the first to investigate the effects of infiltration/exfiltration on sediment transport in the swash zone using a field study. Seepage

\footnotetext{
${ }^{1}$ School of Engineering, University of Aberdeen, Aberdeen, UK.

${ }^{2}$ Department of Civil and Environmental Engineering, Hong Kong University of Science and Technology, Kowloon, Hong Kong.

Copyright 2011 by the American Geophysical Union. 0148-0227/11/2010JC006789
}

alters the effective weight of sediment [Nielsen, 1992] and also affects bed shear stress [Puleo and Holland, 2001] by thinning (infiltration) or thickening (exfiltration) the bottom boundary layer of the swash flow [Conley and Inman, 1994]. Infiltration increases the effective weight of the sediment and therefore impedes its transport, but may also increase the bed shear stress, thereby promoting sediment transport. Nielsen [1997], Turner and Masselink [1998], and Butt et al. [2001] included the two processes, i.e., bed stabilisation/destabilisation, and the boundary layer alteration into a modified version of the Shields parameter, considering the net effect on sediment transport of these (opposing) mechanisms across saturated beds in the swash zone. Butt et al. [2001] define a threshold with regard to a critical sediment size and/or hydraulic conductivity below which infiltration and exfiltration promote offshore transport and above which infiltration and exfiltration promote onshore transport. Infiltration also induces swash flow asymmetry. As a result of water being lost to the beach the uprush water flux is greater than the backwash flux, thus reducing water volume and shortening the duration of the backwash [Austin and Masselink, 2006]. This flow asymmetry, which increases for coarser beaches, causes an asymmetry between the net uprush and net backwash sediment transport. 


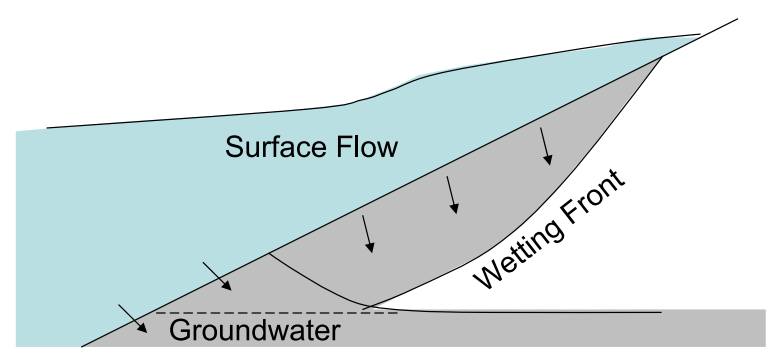

Figure 1. A bore-driven swash event.

Researchers generally agree that infiltration and exfiltration processes are likely to increase onshore transport on coarser beaches [e.g., Horn and Li, 2006], which in turn affects the beach slope. Thus the coarser the material, the greater the role that has been played by infiltration and the steeper the beach [Bagnold, 1940; Masselink and Li, 2001].

[4] Infiltration into the beach is driven by the weight of the surface water. In the upper, initially unsaturated region of a coarse-grained beach the infiltrated water forms a wetting front, which advances by replacing the air within the voids of the porous material with water until the front reaches the groundwater level (Figure 1). Air entrapped between the wetting front above and the groundwater table below can significantly impact the infiltration and exfiltration process in natural beaches [Horn, 2002, 2006]. Soil studies found that air entrapment greatly reduces the hydraulic conductivity and hence decreases the infiltration rates [Constantz et al., 1988; Faybishenko, 1995].

[5] Most previous research into swash zone processes has involved sandy beaches (typically around $d_{50}=0.5 \mathrm{~mm}$ ), but relatively little attention has been given to coarsegrained beaches. Horn [2006] identified important research questions related to the subsurface hydrodynamics in the swash zone, such as the variability of hydraulic conductivity, air entrapment, the effects of pressure gradients, infiltration and exfiltration processes on sediment transport, for coarse-grained beaches in particular. A lack of knowledge is especially apparent when it comes to the influence of the unsaturated and partially saturated region above the groundwater table on flow and pressure distribution within the beach.

[6] In complex field conditions it is difficult if not impossible to isolate and study the key processes affecting swash on beaches; this is best achieved through controlled laboratory experiments. For the present study, in which we study infiltration and exfiltration processes, we conduct experiments on a permeable but immobile beach of known permeability. So far, to the authors' knowledge, the only previous laboratory experiments carried out on a permeable and immobile bed are those reported by Lara et al. [2006]. However, those experiments focused on hydrodynamics in the surf zone, not swash.

[7] The aim of the present work is to improve fundamental understanding of the interaction between bore-driven swash and the subsurface flow within the beach. The main parameters which control this interaction are the beach sediment size (determining beach permeability and roughness) and the initial groundwater level within the beach. The influence of these parameters is investigated by conducting a series of large-scale laboratory swash experiments on permeable immobile beaches. This paper reports the surface and subsurface flow measurements, focused on the infiltration, exfiltration and pressure behavior within the permeable beach during swash.

[8] The paper is organized as follows. Section 2 describes the laboratory setup for the large-scale experiments of boredriven swash on permeable, but immobile coarse-grained beaches, detailing the test facility and measurement techniques. The experimental results are discussed in sections 3-6. Section 3 presents the main features of the surface and subsurface flow during the uprush and backwash stages of the swash cycle, including water profiles and time series of wetting front, infiltration rates and infiltrated volume. Section 4 focuses on pressure within the beach, with special attention paid to the effect of air encapsulation within the unsaturated region of the beach. In section 5 the results from the sections 3 and 4 are used to evaluate the vertical hydraulic gradients during the swash cycle. Section 6 presents the response of the groundwater to infiltration. Finally, section 7 summarizes and concludes this paper.

\section{Experimental Methodology}

\subsection{Test Facility}

[9] The facility consists of a $20 \mathrm{~m}$ long, $0.9 \mathrm{~m}$ high, and $0.45 \mathrm{~m}$ wide, glass-sided flume with a water reservoir at one end (Figure 2). A gate fronting the reservoir can be raised very quickly to produce a plunging wave. A bore is generated which propagates to the beach and leads to swash excursions of magnitude typical of natural beaches. Swash events produced by the test facility have excellent repeatability [O'Donoghue et al., 2010].

[10] In the majority of experiments the reservoir was filled to a depth of $0.60 \mathrm{~m}$ producing an approximately $0.25 \mathrm{~m}$ high bore with a velocity of approximately $2 \mathrm{~m} / \mathrm{s}$ at the toe of the beach. The bore travels horizontally along the bottom

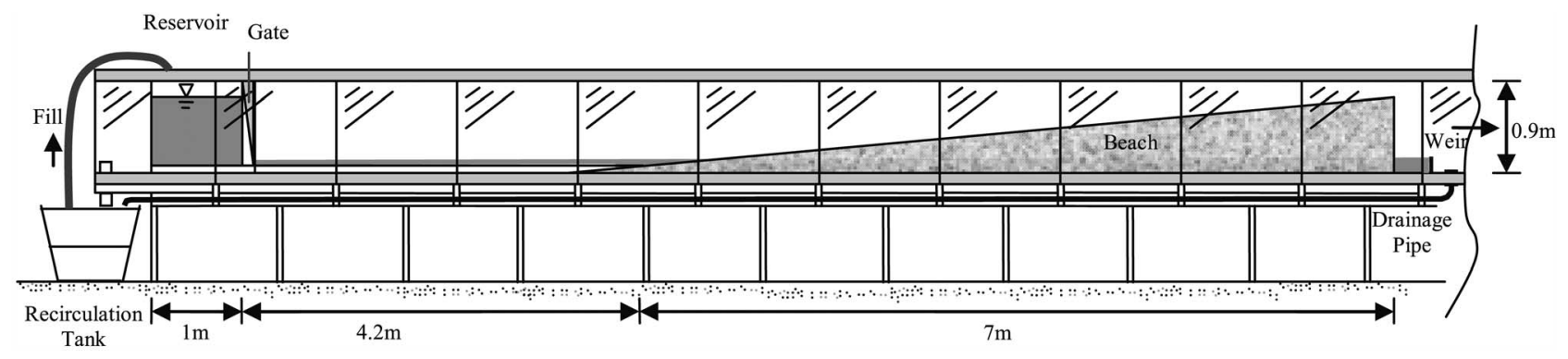

Figure 2. The swash facility. 


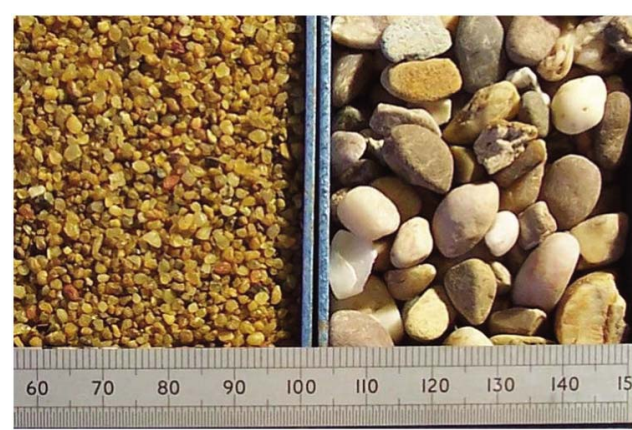

Figure 3. Sediment samples.

of the flume before running onto a 1:10 beach located $4 \mathrm{~m}$ downstream of the reservoir, producing swash excursions ranging from 3 to $4 \mathrm{~m}$ depending on the beach material.

[11] The beach was made of sediment throughout its depth with the top $30 \mathrm{~mm}$ bonded by a dilute water-cementsediment mix (ratio of approximately 1:2:67 by weight), thereby maintaining the permeability and roughness but preventing the sediment from moving. The experiments involved two beach materials: one with nominal diameter $d=1.5 \mathrm{~mm}$ and another with $d=8.5 \mathrm{~mm}$. Samples of the two sediment types are shown in Figure 3.

\subsection{Characterizing the Porous Media}

[12] The hydraulic resistance to the flow through the two types of granular material was investigated using a purpose-built constant head apparatus which consisted of a $185 \mathrm{~mm}$ diameter cylinder with $405 \mathrm{~mm}$ high sediment sample. Figure 4 shows these measurements in the form of hydraulic gradient, $I$, versus the Darcy velocity, $u_{D}$, defined as the ratio of discharge and the cross-sectional area of the apparatus.

[13] The same apparatus was used to measure the hydraulic resistance of the two granular materials with a top layer bonded by cement. Figure 4 shows that the measurements with the cement-sediment layer (triangles) agree well with those of the original sediment samples. This proves that the sediment bonded by cement maintained, up to the range of experimental error, identical hydraulic resistance as the original sediment.

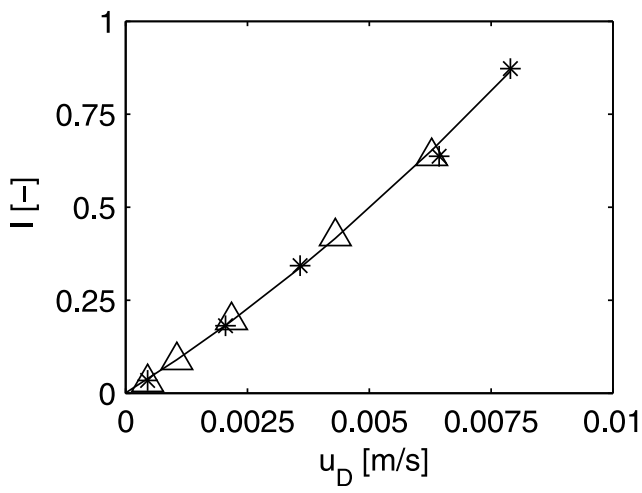

[14] The Forchheimer resistance law, $I=a_{K} u_{D}+b_{K} u_{D}^{2}$ [Fand et al., 1987], was fitted to the data shown in Figure 4. The resulting Forchheimer coefficients were $a_{K}=81.2 \mathrm{~s} / \mathrm{m}$, $b_{K}=3587 \mathrm{~s}^{2} / \mathrm{m}^{2}$ for the $1.5 \mathrm{~mm}$ sediment, and $a_{K}=4.1 \mathrm{~s} / \mathrm{m}$, $b_{K}=383 \mathrm{~s}^{2} / \mathrm{m}^{2}$ for the $8.5 \mathrm{~mm}$ sediment.

[15] The finer sediment is an order of magnitude less permeable than the coarser sediment.

\subsection{Experimental Conditions}

[16] The main experiments were designed to explore the effect of the beach permeability on the water exchange between surface and subsurface flow, for typical initial beach conditions with the groundwater table close to the mean seawater level and an unsaturated beach above this level. The two main experimental series were therefore performed with different sediment and otherwise identical parameters: water depth in the reservoir $H_{0}=600 \mathrm{~mm}$; initial surface water depth in front of the beach $h_{0}=62 \mathrm{~mm}$; initial groundwater level within the beach $\eta_{0}=62 \mathrm{~mm}$. Figure 5 illustrates the setup in a Cartesian system with $x$ and $z$ coordinates in the horizontal and a vertical directions, respectively, and with the origin at the initial shoreline position. Time $t=0$ corresponds to the opening of the reservoir gate.

[17] For the coarser $8.5 \mathrm{~mm}$ sediment no capillary fringe was detected above the groundwater table, whereas for the $1.5 \mathrm{~mm}$ sediment the thickness of the capillary fringe was evaluated at $50 \mathrm{~mm}$. Above the groundwater table/top of the capillary fringe the beach saturation corresponded to fully drained conditions (drainage by gravity). These fully drained conditions with the horizontal groundwater table are somewhat idealized, since the groundwater table in natural beaches usually has a bulge underneath the swash zone. The idealized initial conditions were necessary for maintaining repeatability of swash events.

[18] Two additional experiments were carried out, one with an initially fully saturated beach, and one with a stronger bore generated by a water depth in the reservoir of $H_{0}=700 \mathrm{~mm}$.

[19] Table 1 lists the main experimental conditions for all four experiments. Each experiment has a name which provides a code for the main conditions: " $R 60$ " and " $R 70$ " mean $H_{0}=600$ and $H_{0}=700 \mathrm{~mm}$, respectively; "PER" and "SAT" mean initially unsaturated and saturated beach,

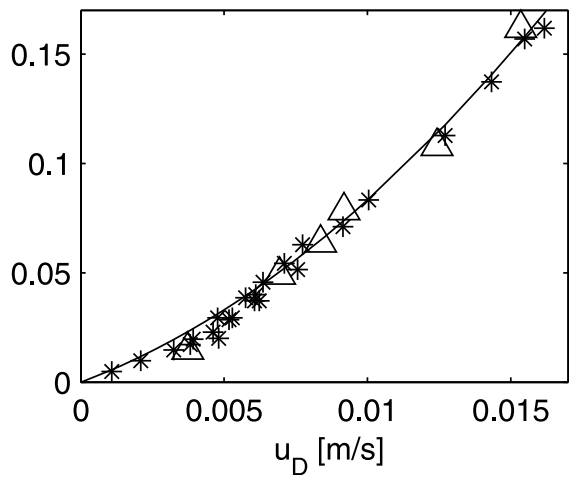

Figure 4. Hydraulic gradient versus Darcy velocity for the (left) 1.5 and (right) $8.5 \mathrm{~mm}$ sediment. Triangles denote measurements for the cement-sediment mixture. Stars denote original sediment sample without cement. 


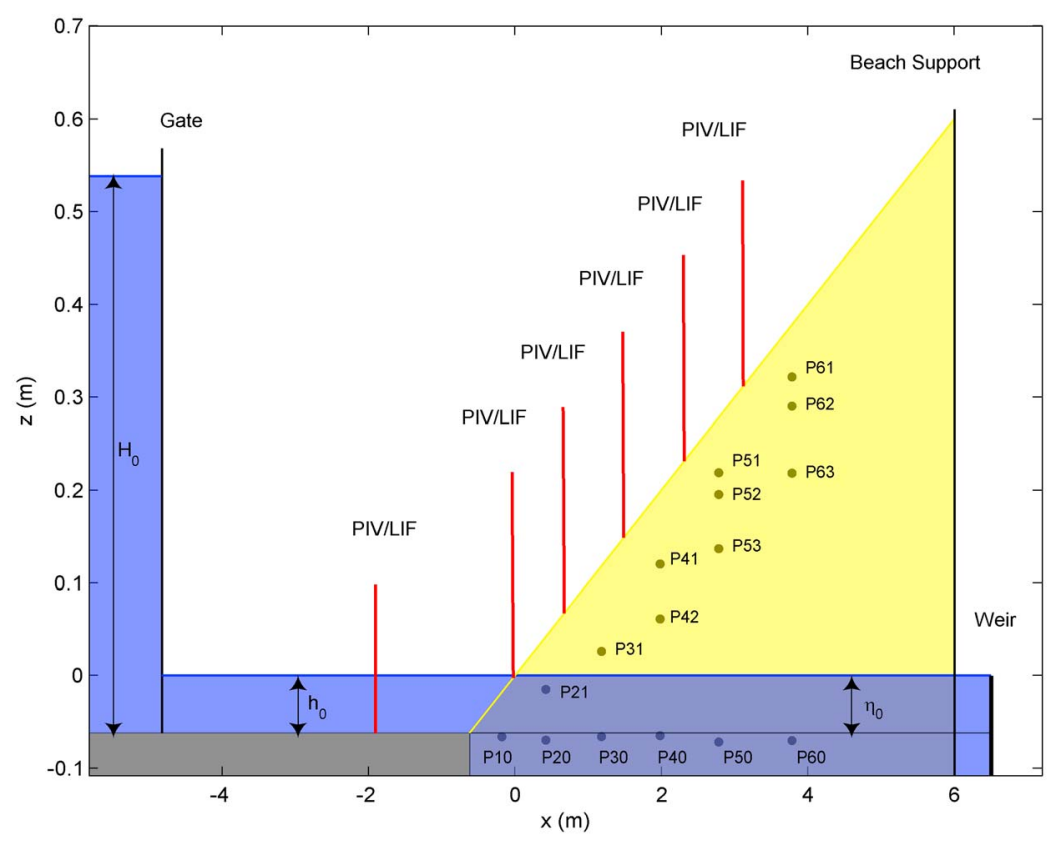

Figure 5. Experimental setup showing 16 pressure transducers and 6 window positions for the simultaneous recording of the LIF and PIV images for the $1.5 \mathrm{~mm}$ beach (R60PER015).

respectively; " 015 " and " 085 " mean nominal diameter $d=$ 1.5 and $d=8.5 \mathrm{~mm}$, respectively.

[20] Table 1 also lists the types of measurements carried out for each experiment, i.e., surface flow depth and velocity measurements using laser-induced fluorescence (LIF) and particle image velocimetry (PIV), measurements of pressure within the beach, and measurements of the wetting front (WET). Details of these measurements are presented later in this section. Experimental runs were repeated in order to obtain ensemble-averaged results. Between subsequent runs water that infiltrated into the beach had to be drained to ensure identical initial conditions for repeated runs. Figure 6 shows the recovery period recorded by a transducer positioned below the initial groundwater level at $x=2780 \mathrm{~mm}$ for both beaches. The recovery period was determined by recording the water level in the saturated area of the beach prior, during and after a single swash run. Lower permeability resulted in a much longer recovery time for the $1.5 \mathrm{~mm}$ beach, of approximately 60 minutes, compared to approximately 6 minutes for the $8.5 \mathrm{~mm}$ beach.

\subsection{Surface Flow Measurements}

[21] A series of detailed surface flow measurements were undertaken using LIF to measure the swash depth and PIV to measure instantaneous velocity fields. The LIF $(1 \mathrm{M} \mathrm{b} / \mathrm{w})$ and PIV $(2 \mathrm{M} \mathrm{b} / \mathrm{w})$ digital cameras captured images of the flow, which was illuminated by a Nd YAG Laser and contained fluorescent dye and seeding particles. The two measuring techniques of the surface flow are discussed in greater detail by G. A. Kikkert et al. (Experimental study of bore driven swash hydrodynamics on impermeable slopes, submitted to Experiments in Fluids, 2011).

[22] Simultaneous depth and velocity measurements were carried out at several cross-shore locations for the 1.5 and $8.5 \mathrm{~mm}$ beach (Figure 5). In order to obtain accurate velocity statistics the number of repeats was as large as practically feasible: 50 for the $8.5 \mathrm{~mm}$ beach and 15 for the $1.5 \mathrm{~mm}$ beach, the latter reduced for practical reasons, i.e., because of the much longer recovery period.

[23] To capture most of the surface flow profile (the so-called swash lens), additional swash depth measurements for the 1.5 and $8.5 \mathrm{~mm}$ beach were carried out at multiple camera positions along the beach ( 8 and 12 camera positions for the 1.5 and $8.5 \mathrm{~mm}$ sediment, respectively). Ensemble averages of swash depth are more stable than velocity statistics, so it was sufficient to have a fewer number of repeats (10 for the $8.5 \mathrm{~mm}$ beach and 8 for the $1.5 \mathrm{~mm}$ beach).

[24] In the experiment with the reservoir depth of $700 \mathrm{~mm}$, swash depth was measured only at the crossshore locations with the vertical arrays of pressure transducers, and the number of repeats was 10 .

[25] For all LIF and PIV measurements the duration of the recording was long enough to capture the entire swash event of $10 \mathrm{~s}$; the sampling rate was $13.5 \mathrm{~Hz}$.

[26] Only the ensemble-averaged depths are presented in this paper. More detailed results of the surface flow measurements are presented by Kikkert et al. (submitted manuscript, 2011).

Table 1. Main Experimental Conditions and Measurements for the Three Series with PIV, LIF, WET, and SAT ${ }^{\mathrm{a}}$

\begin{tabular}{ccccccccc}
\hline Series & $\begin{array}{c}d_{50} \\
(\mathrm{~mm})\end{array}$ & $\begin{array}{c}h_{0} \\
(\mathrm{~mm})\end{array}$ & $\begin{array}{c}\eta_{0} \\
(\mathrm{~mm})\end{array}$ & $\begin{array}{c}H_{0} \\
(\mathrm{~mm})\end{array}$ & LIF & PIV & Pressure & WET \\
\hline R60PER015 & 1.5 & 62 & 62 & 600 & $\mathrm{X}$ & $\mathrm{X}$ & $\mathrm{X}$ & $\mathrm{X}$ \\
R60PER085 & 8.5 & 62 & 62 & 600 & $\mathrm{X}$ & $\mathrm{X}$ & $\mathrm{X}$ & $\mathrm{X}$ \\
R70PER085 & 8.5 & 62 & 62 & 700 & $\mathrm{X}$ & & $\mathrm{X}$ & \\
R60SAT015 & 1.5 & 62 & SAT & 600 & & & $\mathrm{X}$ & \\
\hline
\end{tabular}

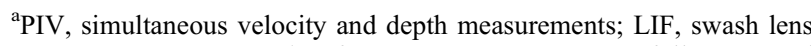
measurements; WET, wetting front measurements; SAT, fully saturated beach. Figure 5 illustrates the definitions of $\eta_{0}, h_{0}$, and $H_{0}$. 


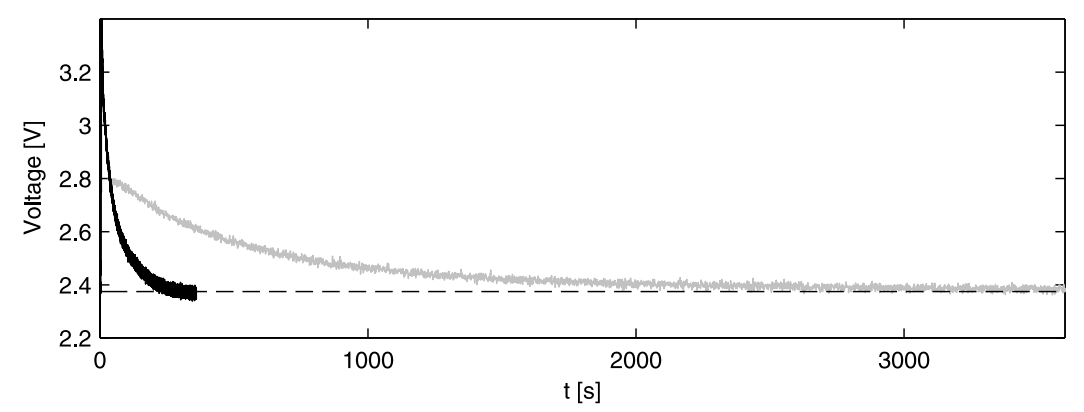

Figure 6. Drainage of the beach after an experimental run shown as a pressure signal at $x=2780 \mathrm{~mm}$ within the 1.5 (grey line) and $8.5 \mathrm{~mm}$ (black line) beach in experiment R60PER015 and R60PER085, respectively. Initial groundwater level is indicated by the horizontal dashed line.

\subsection{Pressure Measurements}

[27] Pressure transducers were used to measure the pressure at a series of locations within the beach. The setup for the $1.5 \mathrm{~mm}$ beach is shown in Figure 5. The arrangement for the $8.5 \mathrm{~mm}$ beach was very similar. The transducers were positioned in vertical arrays midway between the surface flow PIV/LIF measurement locations. Each profile contains a bottom transducer, placed below the initial groundwater level and named $P_{i 0}$, with $i$ indicating the profile number increasing in the onshore direction. The remaining transducers were placed above $P_{i 0}$, at the same cross-shore locations, so that they were above the initial groundwater level in all experiments except R60SAT015. They are labeled $P_{i j}$, with $j$ indicating the vertical position of transducer within the profile ( $j=1$ is the shallowest position and $j$ increases downward). The number of transducers $P_{i j}$ within the individual profiles was variable. Table A1 in Appendix A presents the transducers' positions for the beaches.

[28] Two types of pressure transducer were used: Druck transducers and in-house built transducers. All transducers have a length of approximately $60 \mathrm{~mm}$ and a diameter of approximately $30 \mathrm{~mm}$. The Druck 4-20 mA gauge (series PTX 7533) has a pressure range between 0 and 100 mbar. Their overall performance, repeatability and accuracy is very good with an error of approximately $0.15 \%$ of the whole range (equivalent to an error of $1.5 \mathrm{~mm}$ water depth).
The main electronic component of the in-house transducer consists of either a Honeywell 26PC01SMT 70 mbar range sensor or Sensortechnics RQOP005D 300 mbar range sensor. The sensor component of the in-house transducer had the biggest error, with approximately $1 \%$ of the whole range, which is equivalent to an error of $7 \mathrm{~mm}$ water depth for the Honeywell sensors and $30 \mathrm{~mm}$ water depth for the Sensortechnics sensors. For both types of transducer the errors were significantly reduced by calibration over the required pressure range. The calibration was performed in situ, by filling the flume and recording pressures for known water depths. Further reduction of error was achieved by ensemble averaging over the repeated runs, as explained below.

[29] The data acquisition software (VI Logger) controlled the timing and the sampling rate of the pressure transducers connected to the acquisition board (National Instruments DAQPad-6016) of the pressure system. Pressure signals from 50 individual swash runs (16 in the case of the initially fully saturated $1.5 \mathrm{~mm}$ beach, R60SAT015) were recorded, with a duration of $30 \mathrm{~s}$ and sampling frequency $135 \mathrm{~Hz}$, i.e., 10 times the rate of the PIV/LIF system. Figure 7 shows examples of the ensemble-averaged voltage signals together with the individual signals for a transducer of the $1.5 \mathrm{~mm}$ beach. A time series of the root mean square error (rms) of pressure for each transducer was used for extracting an average value of RMS over the duration of the swash cycle.
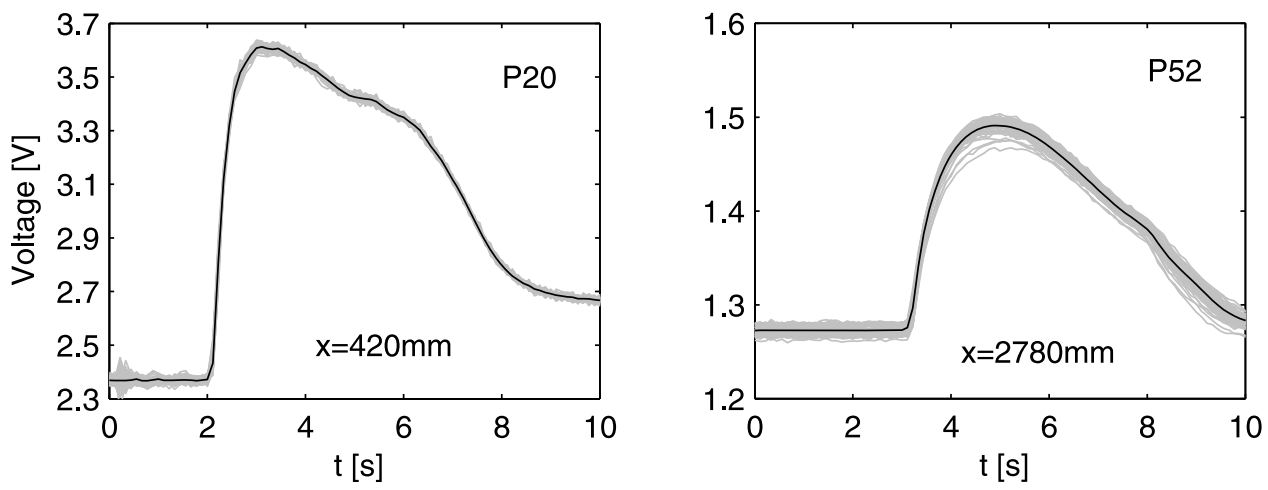

Figure 7. Time series of individual (grey lines) and ensemble averaged (black line) pressure signal for a Druck transducer at $x=420 \mathrm{~mm}\left(P_{20}\right)$ and an in-house transducer at $x=2780 \mathrm{~mm}\left(P_{52}\right)$ within the $1.5 \mathrm{~mm}$ beach (R60PER015). 


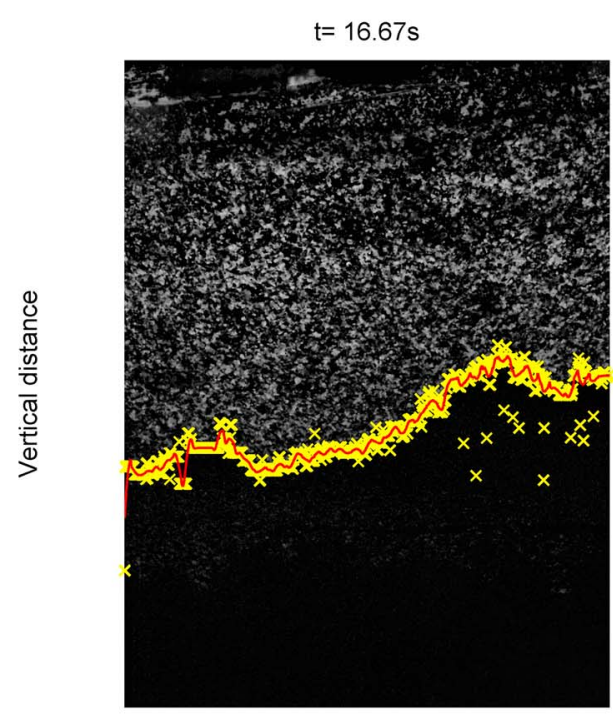

Horizontal distance

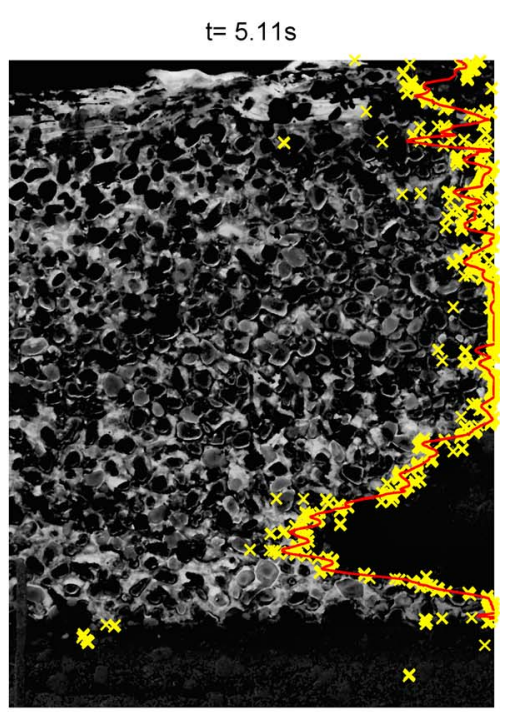

Horizontal distance

Figure 8. Wetting front detection at $x=2608 \mathrm{~mm}$ within the (left) 1.5 and (right) $8.5 \mathrm{~mm}$ beach of experiment R60PER 015 and R60PER085, respectively. Note that the direction of bore travel during uprush is from left to right. In the $8.5 \mathrm{~mm}$ beach it was also possible to detect the groundwater level because there was no capillary fringe above it.

The average RMS value (in $\mathrm{mm}$ ) for the Druck and in-house transducers of the main experiments (R60PER015 and R60PER100) is presented in Table A1. All RMS values fall within the range of $0.5-2.5 \mathrm{~mm}$.

\subsection{Wetting Front Measurements}

[30] The movement of the water/air interface within the beach was recorded through the glass sidewall of the flume. The weakness of the method is that the movement of the wetting front at the wall may be somewhat altered by the wall effect. However, these measurements provided useful insight into the shape and speed of the wetting front. Furthermore, the explicit tracking of water proved helpful for interpreting the pressure measurements. The digital camera $(2 \mathrm{M} \mathrm{b} / \mathrm{w})$ recorded flow images over an area with dimensions approximately $200 \times 300 \mathrm{~mm}(1200 \times 1600$ pixels $)$, capturing the propagation of the wetting front from bed surface until it reached the top of the capillary fringe or the groundwater level.

[31] Image analysis started with subtracting the initial image, showing the porous material prior to the swash event, from all subsequent images. A two-step MATLAB algorithm was then used to identify the interface between the saturated and unsaturated region of the beach. Figure 8 shows examples of the wetting front and groundwater position across the recorded image detected by the algorithm for the 1.5 and $8.5 \mathrm{~mm}$ beach. The crosses represent the result of the first step, which consists of detecting the first pixels where the intensity is greater than a predetermined tolerance value. For the $1.5 \mathrm{~mm}$ sediment searching is performed over pixel columns in the bottom-up direction, whereas for the $8.5 \mathrm{~mm}$ sediment it is done over pixel rows, from right to left. The signal obtained in this way is noisy, so the second step of the algorithm applies a Savitzky-Golay filter which results in the data shown as the solid line in Figure 8. The right-to-left direction of searching used for the $8.5 \mathrm{~mm}$ sediment allowed detection of the groundwater level. However, it also produced a series of erroneous points near the right edge of images for all time instances when the tip of the wetting front has gone past the image. These points can be seen in Figure 8 (right). They were ignored in all subsequent calculations.

[32] The detection of the front could not be achieved at pixel resolution because of the low contrast and high noise of the images. It was estimated that the error in vertical position of the wetting front is of the order of the sediment diameter. In the $1.5 \mathrm{~mm}$ beach a capillary fringe of approximately $50 \mathrm{~mm}$ above the initial groundwater level was present, i.e., the front could not be tracked within this region of the beach. Furthermore, it was not possible to detect the upper edge of the saturated region above the wetting front which forms at early stages of the backwash.

[33] Dynamic Studio v1.45 (DANTEC Dynamics) was used for data acquisition, timing and controlling the sampling rate of the wetting front images. The wetting front recordings were performed at a series of cross-shore locations (12 positions between $x=1023$ and $4242 \mathrm{~mm}$, i.e., around maximum runup, for the $1.5 \mathrm{~mm}$ beach and 7 positions between $x=1313$ and $3179 \mathrm{~mm}$, i.e., around maximum runup, for the $8.5 \mathrm{~mm}$ beach). The number of repeats of the wetting front measurements at each location was 4 for the $8.5 \mathrm{~mm}$ beach, and 2 for the $1.5 \mathrm{~mm}$ beach, the latter reduced for practical reasons. The recording frequency for the $8.5 \mathrm{~mm}$ beach was $13.5 \mathrm{~Hz}$ with a duration of $10 \mathrm{~s}$. Due to low permeability, the recording frequency for the $1.5 \mathrm{~mm}$ beach was $4.5 \mathrm{~Hz}$ and the duration was $30 \mathrm{~s}$. Figure 9 shows wetting front measurements from repeated runs and the ensemble-averaged wetting front at $x=$ $2608 \mathrm{~mm}$ at two selected times for the 1.5 and $8.5 \mathrm{~mm}$ beaches. For each beach, one of the individual runs shown in Figure 9 (bottom) corresponds to an image in Figure 8. 

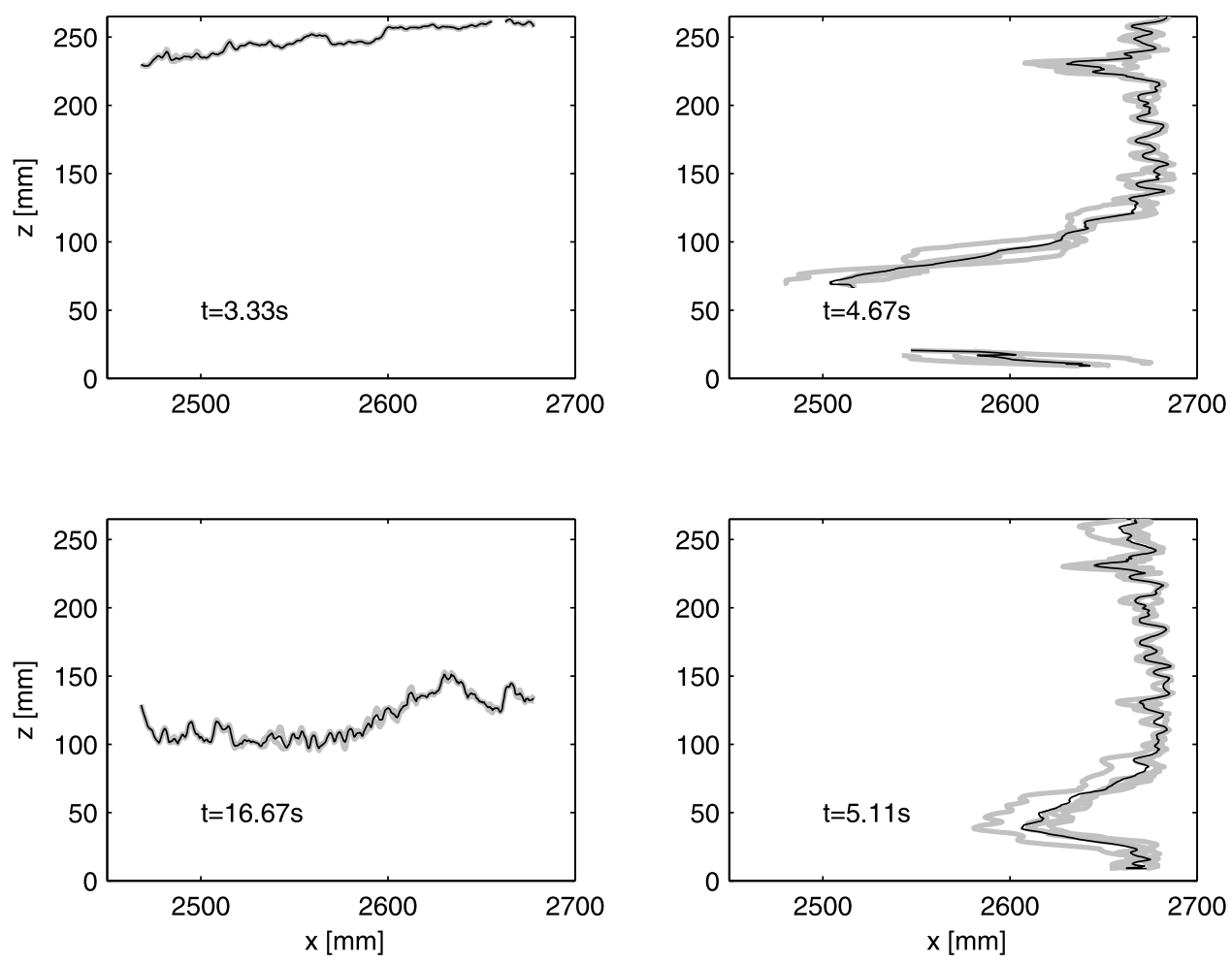

Figure 9. Example of ensemble-averaged wetting front (black line) and individual runs at $x=2608 \mathrm{~mm}$ for two selected times within the (left) 1.5 and (right) $8.5 \mathrm{~mm}$ beaches in experiment R60PER015 and $R 60 P E R 085$, respectively. Note that the direction of bore travel during uprush is from left to right.

[34] Table B1 in Appendix B lists the $x$ locations of the centers of the camera views and the physical dimensions of the camera views for the two beaches.

\section{Infiltration Into the Beach}

[35] Figure 10 shows a definition sketch for all relevant flow quantities presented in the remaining text.

\subsection{Water Profiles}

[36] During bore propagation water from the surface flow infiltrated into the beach, forming a wetting front profile below the beach surface. Figure 11 shows water profiles across the swash zone for both beaches. They consist of a surface profile, showing the surface flow level, $z_{h}$, and the subsurface profile, which shows the position of the wetting front, $z_{f}$.

[37] The different permeability of the two beaches results in very different speeds of the wetting front. This is clearly visible at $t=3.78 \mathrm{~s}$, when the wetting front within the $1.5 \mathrm{~mm}$ beach is very close to the beach surface for the whole subsurface profile, whereas in the $8.5 \mathrm{~mm}$ beach the wetting front has reached the groundwater level over approximately half of the profile (until $x \sim 1900 \mathrm{~mm}$ ), and has traveled a significant depth over the remaining $500 \mathrm{~mm}$. These distinctly different depths of penetration for the wetting front indicate that the volume of water infiltrating into the $1.5 \mathrm{~mm}$ beach is considerably smaller than for the $8.5 \mathrm{~mm}$ beach.

[38] During uprush the most shoreward points of the surface and the subsurface profiles are very close, with the former moving slightly ahead. This means that close to the bore tip infiltration into the beach starts very quickly after the bore arrival.

[39] The location and time of maximum runup of the surface flow are different for the two beaches: $4396 \mathrm{~mm}$ and $t=5.26 \mathrm{~s}$ for the $1.5 \mathrm{~mm}$ beach, compared to $3040 \mathrm{~mm}$ and $t=4.44 \mathrm{~s}$ for the $8.5 \mathrm{~mm}$ beach. The bore on the $1.5 \mathrm{~mm}$ travels further and for longer than on the $8.5 \mathrm{~mm}$ beach for two reasons: the volume of water lost to the beach by infiltration is smaller, and the less rough bed surface is less efficient in extracting momentum from the surface flow.

[40] Careful inspection of the subsurface profiles for the $8.5 \mathrm{~mm}$ beach at $t=3.78 \mathrm{~s}$ and $t=4.44 \mathrm{~s}$ reveals a slight elevation of the groundwater level, $z_{\eta}$, below the wetting front (few points at the base of the subsurface profile close

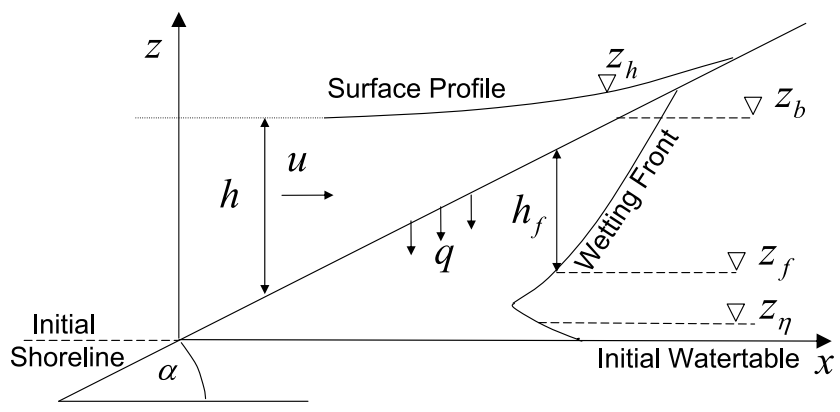

Figure 10. Definition sketch for flow quantities. 

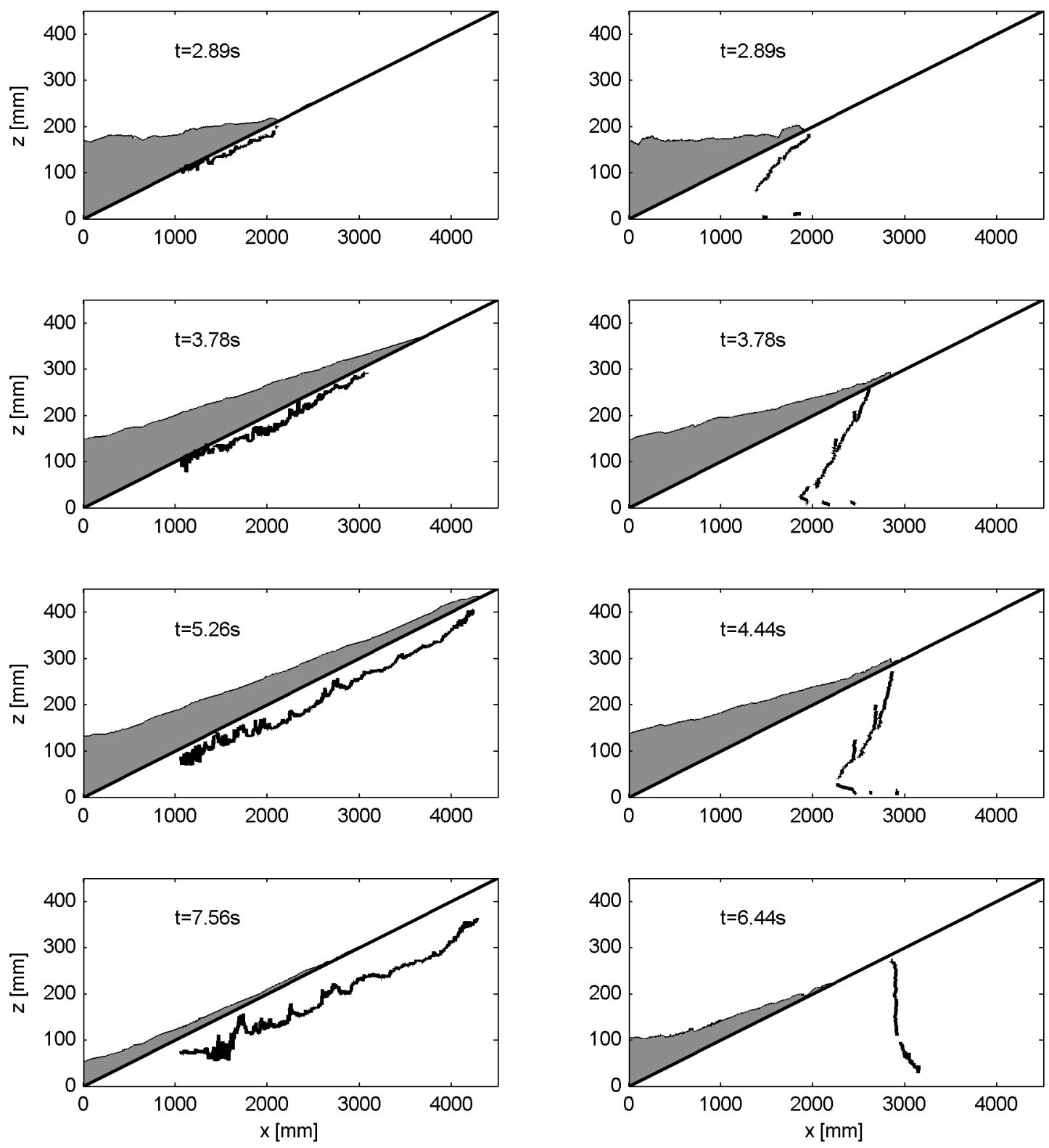

Figure 11. Surface and subsurface water profiles at several selected times for the (left) 1.5 and (right) $8.5 \mathrm{~mm}$ beach of experiment R60PER015 and R60PER085, respectively.

to $z=0$ ). This elevation indicates a horizontal hydraulic gradient which generates groundwater flow in the shoreward direction.

[41] During backwash the intersection of the subsurface profile with the beach face remains at a very high position. At the same time the surface profile rapidly retreats so that the shoreline position quickly travels down the slope. The part of the beach face between the two points (i.e., end of the subsurface profile and the shoreline) becomes a so-called seepage face, defined as the boundary where the saturated pore pressures are atmospheric. The seepage face is clearly visible at $t=6.44 \mathrm{~s}$ for the $8.5 \mathrm{~mm}$ beach.

[42] Close to the end of the swash event the subsurface conditions within the two beaches are distinctly different. In the $1.5 \mathrm{~mm}$ beach the wetting front remains above the top of the capillary fringe $(z=50 \mathrm{~mm})$ for the majority of the subsurface profile. In contrast, in the $8.5 \mathrm{~mm}$ beach the wetting front has completely merged with the groundwater.

\subsection{Wetting Front Propagation}

[43] Infiltration into the beach at a particular cross-shore location is presented as a time series of the wetting front level, $z_{f}(x, t)$, within the two beaches in Figure 12. Each time series starts at the beach surface at the moment of bore arrival at the particular location and shows how the wetting front moves downward. The wetting front level within the $1.5 \mathrm{~mm}$ beach decreased gradually in time, whereas the movement of the wetting front within the $8.5 \mathrm{~mm}$ beach tracks a much steeper line and shows little sign of slowing down during the swash cycle. 

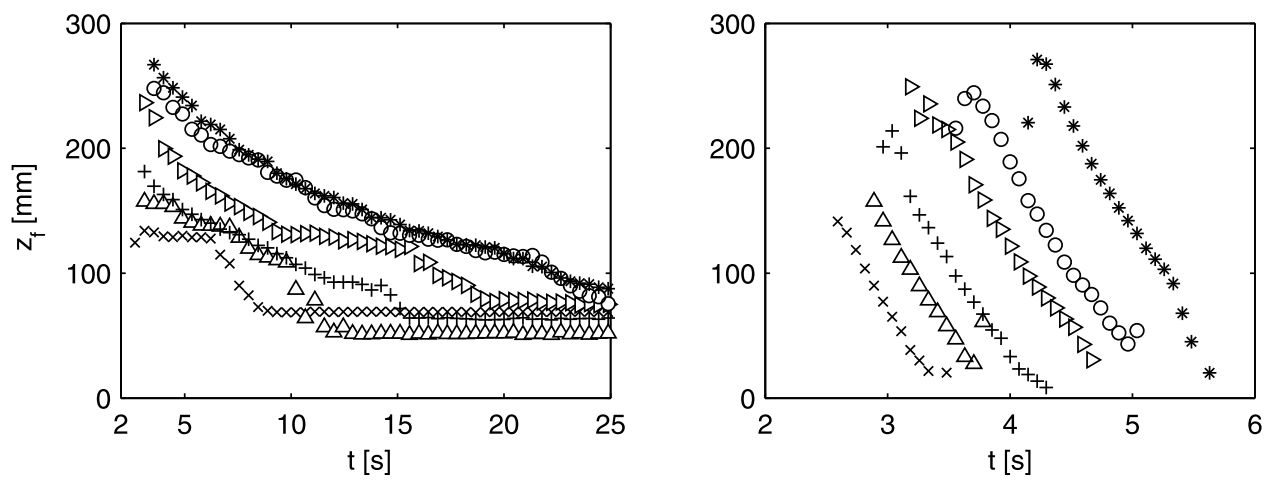

Figure 12. Time series of wetting front for the (left) 1.5 and (right) $8.5 \mathrm{~mm}$ beach at six cross-shore locations $x=1463$ (crosses), 1763 (triangles), 2063 (pluses), 2378 (tilted triangles), 2608 (circles), and $2838 \mathrm{~mm}$ (stars) of experiment R60PER015 and R60PER085, respectively.

[44] The wetting front is driven by the weight of water within and above the beach, i.e., the driving force is proportional to the vertical hydraulic gradient. As the wetting front propagates, the air within the beach is replaced with water. The fraction of the volume of voids available for infiltration (effective porosity) is $\theta=\theta_{\max }-\theta_{0}$, where $\theta_{\max }$ and $\theta_{0}$ are the maximum water content and the initial water content, respectively. In our experiments the effective porosity was evaluated from separate volumetric measurements to be $\theta=0.3$. This value and the time series of the wetting front speed (gradients of lines shown in Figure 12) were used to determine the infiltration rates, $q$, within the two beaches as

$$
q(x, t)=\theta \frac{d z_{f}(x, t)}{d t}
$$

For the $1.5 \mathrm{~mm}$ beach, the infiltration rates are initially between 4 and $8 \mathrm{~mm} / \mathrm{s}$ and then decrease over time to become relatively constant, at approximately $2 \mathrm{~mm} / \mathrm{s}$. For the $8.5 \mathrm{~mm}$ beach infiltration rates are between 30 and $60 \mathrm{~mm} / \mathrm{s}$.

\subsection{Cumulative Volume of Water Penetrating Into the Beach}

[45] The surface flow loses water to the beach while propagating up and down the slope. The cumulative water

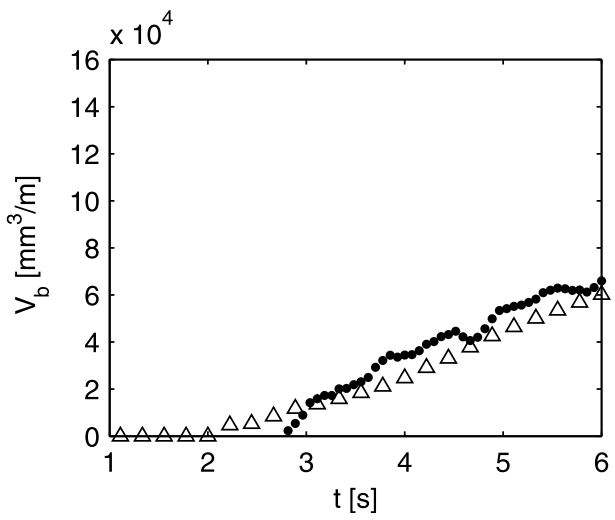

flux across the beach surface was calculated using two independent methods, one based on surface flow data, and one based on subsurface flow data.

[46] Simultaneous time series of depth and velocity were measured at several cross-shore locations. The closest measurement position to the initial shoreline position, $x=0 \mathrm{~mm}$, was $x_{o}=72 \mathrm{~mm}$. This location was therefore chosen for evaluating the discharge which entered the control volume $\left(x>x_{o}\right)$. Due to the air bubbles in the surface flow just after bore arrival there was a gap in the velocity data. Within this period $(0<t<\tau)$ it was assumed that too little time had elapsed for water to infiltrate into the beach, i.e., the infiltration rate across the beach surface was zero during this small time. The volume of water lost to the beach at any time $t$ was calculated from continuity as the difference between the total volume that entered the control volume until $t$ and the volume present on the beach surface at the same time $t$, i.e., as

$$
V_{b}(t)=\int_{\tau}^{t} u\left(x_{o}, t\right) h\left(x_{o}, t\right) d t-\int_{x_{o}}^{x=x_{s}(t)} h(x, t) d x,
$$

where $h$ and $u$ are ensemble-averaged surface flow depth and depth-averaged, ensemble-averaged velocity, respectively, $x_{s}(t)$ is the shoreline position and $\tau$ is the time at

Figure 13. Cumulative volume of water within the (left) 1.5 and (right) $8.5 \mathrm{~mm}$ beach for experiment R60PER015 and R60PER085, respectively, based on subsurface measurements (triangles) and surface measurements (circles).

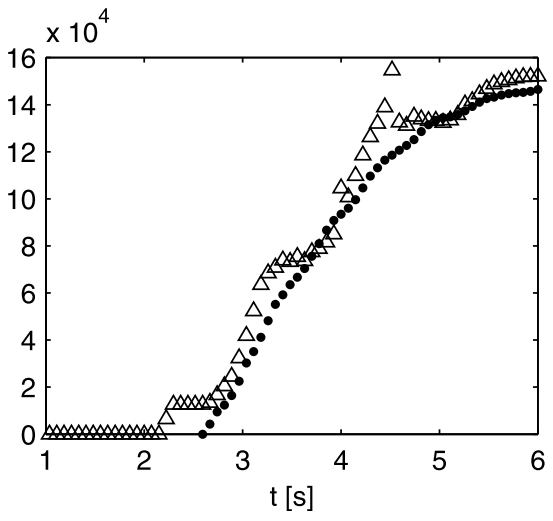



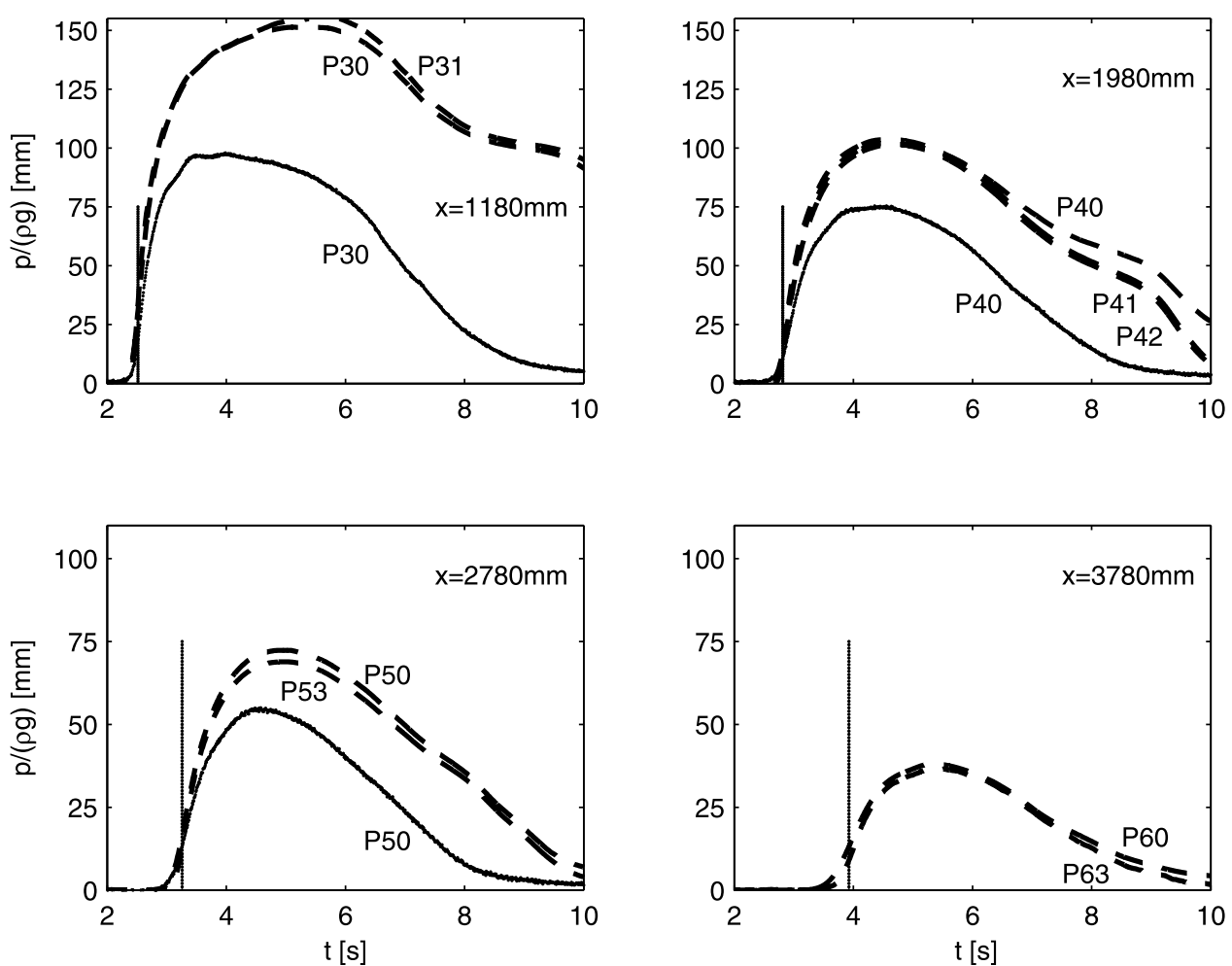

Figure 14. Pressure head time series at $x=1180,1980,2780$, and $3780 \mathrm{~mm}$ for the initially unsaturated (dashed lines) $1.5 \mathrm{~mm}$ beach (R60PER015) and fully saturated (solid lines) $1.5 \mathrm{~mm}$ beach (R60SAT015). The pressure head is expressed relative to the initial pressure. The results for the saturated beach show only measurements of the bottom transducers, i.e., transducers $P_{30}$ at $x=1180 \mathrm{~mm}, P_{40}$ at $x=$ $1980 \mathrm{~mm}$, and $P_{50}$ at $x=2780 \mathrm{~mm}$. The time of bore arrival at each $x$ location for the swash event on the initially unsaturated beach is shown as a vertical line.

which the velocity measurements started $(\tau=0.45 \mathrm{~s}$ for the $1.5 \mathrm{~mm}$ beach and $\tau=0.55 \mathrm{~s}$ for the $8.5 \mathrm{~mm}$ beach).

[47] For the second method time series of the subsurface profiles across the beach were used to evaluate the cumulative volume of water which has entered the beach at time $t$ as

$$
V_{b}(t)=\int_{x=0}^{x=x_{\text {weir }}} \int_{z=0}^{z=z_{b}(x)} \gamma(x, z, t) \theta d z d x
$$

where $x_{\text {weir }}$ is the position of the weir located downstream of the beach at $x=6023 \mathrm{~mm}$ from the initial shoreline position (Figure 5), $\theta$ is the effective porosity and $\gamma(x, z, t)$ is the distribution function which takes the value 1 if the beach is saturated at position $(x, z)$, and is 0 otherwise.

[48] The cumulative volumes of water which penetrated into the beach from the surface flow during the uprush obtained using the two methods are compared in Figure 13. Encouragingly, the two independent methods have produced similar results for the two beaches. This also confirms that the value of 0.3 for the effective porosity from the volumetric measurements is reasonable. By the time of maximum runup the percentage of water volume that has penetrated into the beach of the total water volume that has crossed the lower boundary of the beach was approximately $20 \%$ for the $1.5 \mathrm{~mm}$ sediment and $45 \%$ for the $8.5 \mathrm{~mm}$ sediment. The infiltration result of the $8.5 \mathrm{~mm}$ beach is similar to field measurements undertaken on a $6 \mathrm{~mm}$ beach by Austin and Masselink [2006] and Masselink et al [2010].
They compared uprush with backwash discharges, and concluded that approximately $50 \%$ of the uprush volume infiltrated into the gravel beach.

\section{Pressure Within the Beach}

[49] Pressure measurements within the initially unsaturated beaches were carried out using transducers located at various depths below the beach surface $(50-448 \mathrm{~mm}$, Table A1 in Appendix A). The air within the unsaturated region of the beach is initially at atmospheric pressure. However, the arrival of the bore and the start of infiltration increase the pressure as the air becomes entrapped below the wetting front. The pressure transducers recorded the pore-air pressure, until the moment when the wetting front reached their location. Inspection of the wetting front profiles presented earlier (Figure 11) shows that this occurred very quickly in the $8.5 \mathrm{~mm}$ beach, but did not occur at all (for the duration of a swash event) in the $1.5 \mathrm{~mm}$ beach. As a result, the majority of pressure measurements carried out in the $1.5 \mathrm{~mm}$ beach recorded only pore-air pressure. This section first discusses the pore-air pressure measurements in the $1.5 \mathrm{~mm}$ beach. This is followed by the pressure measurements within the $8.5 \mathrm{~mm}$ beach. The concluding part of the section is focused on horizontal air movement within both beaches.

[50] Figure 14 presents the time series of pressure head, relative to the initial (atmospheric) pressure head, for the 

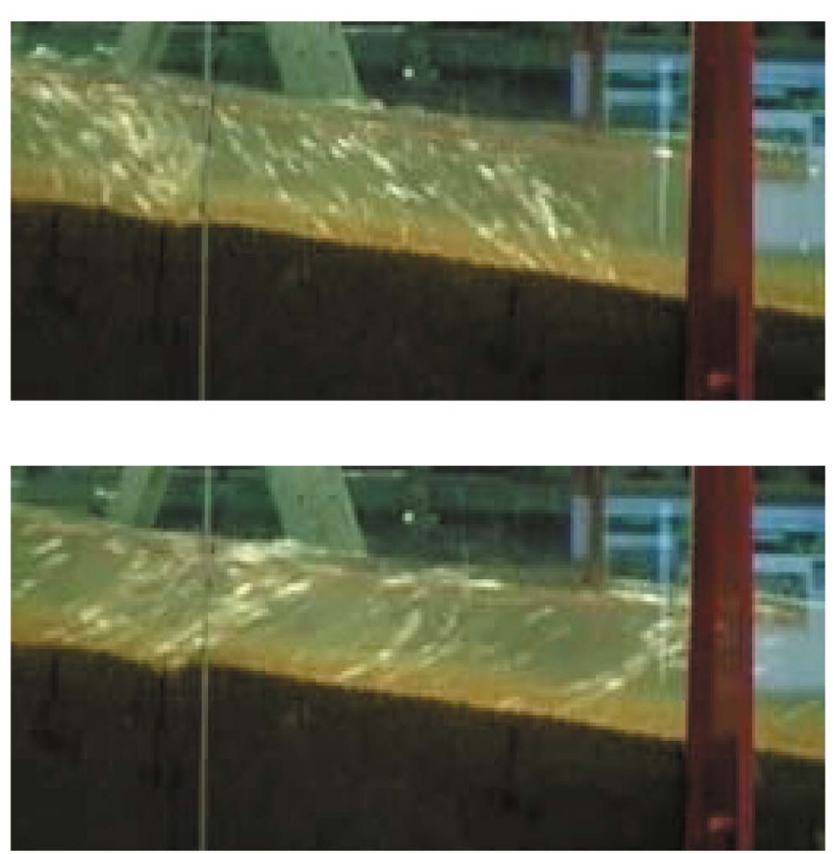

Figure 15. Air released during swash on the $1.5 \mathrm{~mm}$ beach (R60PER015) during (top) uprush and (bottom) backwash. The view corresponds to an approximately $500 \mathrm{~mm}$ flow length at cross-shore location centered at $x=1500 \mathrm{~mm}$.

initially unsaturated $1.5 \mathrm{~mm}$ beach (dashed lines). At each $x$ location there were several pressure transducers positioned at various depths below the wetting front during the whole of the swash cycle. The comparison between the individual pressure head time series at the same location shows that they very closely followed each other, i.e., due to the very low air density approximately identical pressure variation occurred at different vertical locations. This, in addition to the known location of the wetting front, also confirms that these pressure transducers were indeed measuring pore-air pressure.

[51] Figure 14 also shows the time series of pressure head measured by the bottom transducers at $x=1180,1980$, and $2780 \mathrm{~mm}$ in the experiment R60SAT015, with the initially fully saturated beach and otherwise identical conditions (solid lines). The pressure head is expressed relative to the initial pressure, i.e., the initial pressure head has been subtracted. Because the beach was initially fully saturated and the infiltration rates were close to zero, the pressure head in the subsurface closely followed the surface water depth. The surface flow in the two experiments (R60SAT015 and the matching experiment with the initially unsaturated beach, R60PER015) was very similar, so the results for pressure can be compared between the two experiments. The pressure in the initially unsaturated beach did not simply follow the surface water depth. Instead there was a significant buildup of pore-air pressure, which was of similar magnitude to the surface depth itself. At the lower end of the beach $(x=1180 \mathrm{~mm})$ the maximum pressure buildup corresponded to $150 \mathrm{~mm}$ of water, i.e., it was approximately $50 \mathrm{~mm}(50 \%)$ higher than the maximum surface water depth. The interstitial air pressure buildup gradually diminished in the shoreward direction.
[52] The pore-air pressure builds up because air is pushed by the wetting front, and becomes encapsulated between the front and the top of the capillary fringe. The additional poreair pressure creates a horizontal pressure gradient and hence generates interstitial air flow in the shoreward direction. Indeed, comparison of pressure magnitudes at two crossshore locations at any given time shows that there is always a horizontal pressure gradient. As long as the volume of air (per unit time) replaced by the wetting front is larger than the net horizontal air flux, pore-air pressure increases further as the air gets compressed.

[53] Figure 14 also shows that the bore arrival (shown with a vertical line) always occurs slightly later than the beginning of the pressure buildup, and this lag becomes greater further up the slope. This is another consequence of pore-air pressure buildup at lower locations which causes shoreward movement of air and hence increases pore-air pressure slightly ahead of the bore tip.

[54] Close to the end of the backwash, as the wetting front propagation slows down, the pore-air pressure gradually decreases. At the cross-shore location $x=1980 \mathrm{~mm}$ at $t$ around $9 \mathrm{~s}$, close to the end of the backwash, the gradient of the pressure time series suddenly increases indicating faster air release (than earlier at the same location, and simultaneously, but further up the slope). The likely explanation is that the relatively shallow surface water depth in the backwash, combined with the still significant pressure of the entrapped air results in air escaping upward, straight through the surface water. Figure 15 shows evidence of this: even during the uprush pore-air pressure within the $1.5 \mathrm{~mm}$ beach reaches sufficiently large magnitudes with respect to pressure at the beach surface to push the air into the surface flow. The release of air, indicated by the bubbles within the surface flow, is channeled along preferential pathways through the sediment. Similar observations of air under wave runup onto unsaturated sand were also reported by Turner [1993]. This additional mechanism of air release adds considerably to the complexity of the water exchange between the surface and subsurface flows.

[55] The pore-air pressure buildup within the beach lasts until the end of the swash event $(t=10 \mathrm{~s})$. At this stage the wetting front is still propagating toward the groundwater at most locations (Figure 12), but the rate of propagation is much smaller thus allowing the air within the beach to nearly return to its initial atmospheric state (Figure 14).

[56] At this point it is important to make a comment on the applicability of our laboratory results presented above to field conditions. Our laboratory environment creates twodimensional surface and subsurface flow (in $x, z$ plane), such that pore-air below the wetting front can move only in the shoreward direction. This corresponds to an idealized condition where the incident bore approaches a uniform beach slope normally. In such conditions air entrapment and pressure buildup are expected to generate air flow ahead of the incident bore. In realistic field conditions, air may be able to escape laterally due to nonlongshore uniformity of incident bore and beach slope and so the effect of air entrapment will be less pronounced.

[57] In the $8.5 \mathrm{~mm}$ beach the wetting front rapidly reaches the position of the transducers in the initially unsaturated zone of the beach, and from that point on they start to measure the increase in pressure as the result of the presence 

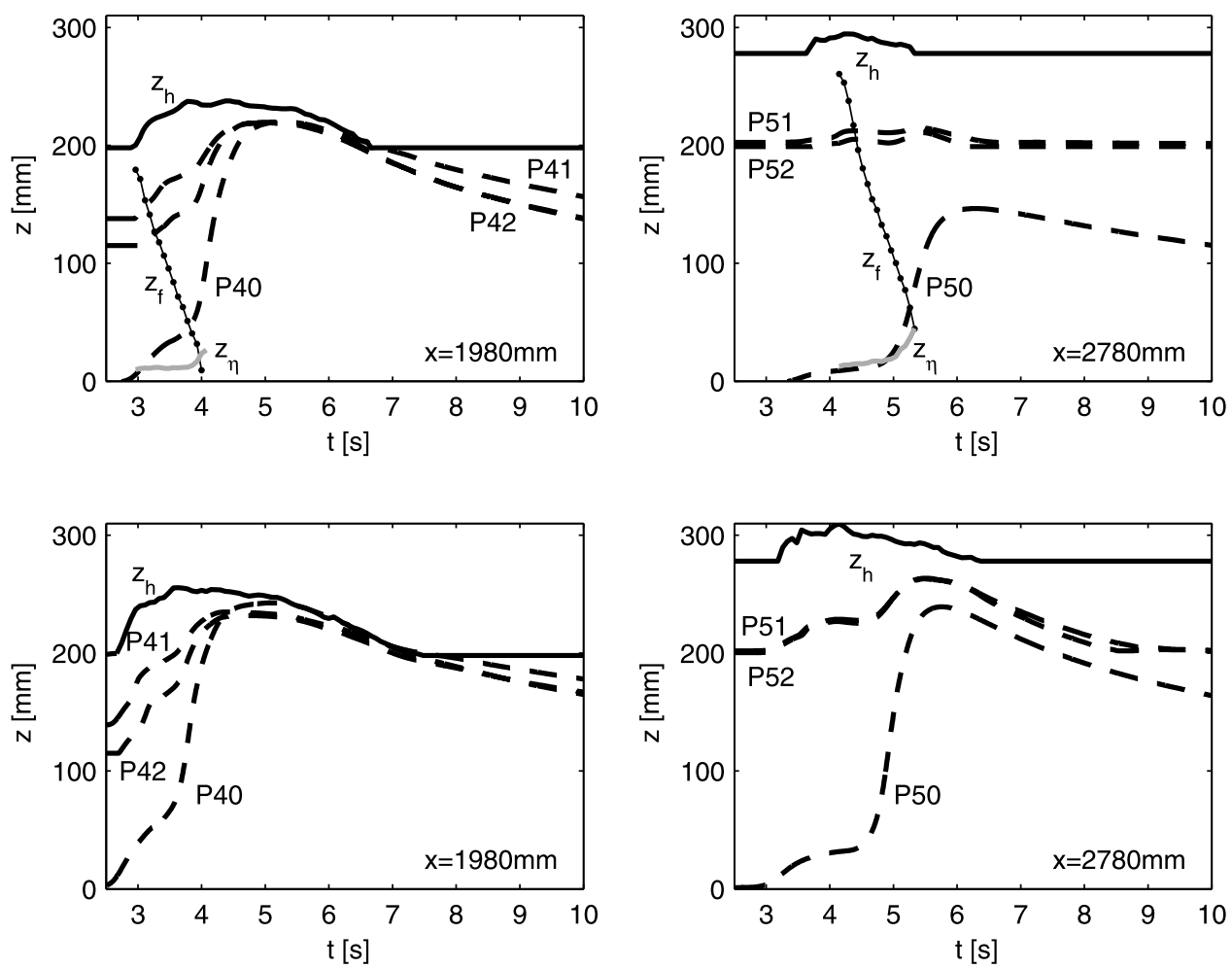

Figure 16. Time series of hydraulic head $h_{p}$ (dashed lines) obtained from pressure measurements, surface water level $z_{h}=z_{b}+h$ (solid line), wetting front level $z_{f}$ (lines with circles), and groundwater level $z_{\eta}$ (grey lines) at $x=1980$ and $2780 \mathrm{~mm}$ for the $8.5 \mathrm{~mm}$ beach with the (top) 600 and (bottom) $700 \mathrm{~mm}$ reservoir depth of experiment R60PER085 and R70PER085, respectively.

of water. It is therefore beneficial to present the pressure measurements in terms of hydraulic head (i.e., sum of the elevation and the pressure head) which determines the direction of water movement.

[58] Figure 16 presents time series of the surface water level and the hydraulic head within the $8.5 \mathrm{~mm}$ beach. Figure 16 (bottom) corresponds to the stronger swash event with $700 \mathrm{~mm}$ reservoir depth, where larger surface water depth and greater runup result in more pronounced changes of pressure within the subsurface than in the $600 \mathrm{~mm}$ experiment. Prior to the bore arrival, the hydraulic heads in Figure 16, indicated by dashed lines, show the level at which the pressure transducers are buried in the bed. After bore arrival the time series of hydraulic head show two distinct regions, one with moderate pressure buildup and another one where the hydraulic head rapidly increases and tends toward the surface water level.

[59] To interpret these results we consider the swash event with the $600 \mathrm{~mm}$ reservoir depth, for which more complete measurements are available (Figure 16, top). Besides hydraulic heads and surface water levels, they also include the time series of the wetting front position $z_{f}$ (lines with circles) and the groundwater level $z_{\eta}$ (grey lines showing a slight increase above $z=0$ ). The wetting front reaches the levels of all individual transducers very quickly after bore arrival. For some time after that, the pressure head variation at all transducers is moderate and closely follows the variation of the surface water depth. This is followed by an abrupt increase in the pressure head time series gradient, which occurs when the wetting front hits the groundwater level (close to $4 \mathrm{~s}$ for $x=1980 \mathrm{~mm}$ and soon after $5 \mathrm{~s}$ for $x=$ $2780 \mathrm{~mm}$ ). From this moment on the hydraulic heads rapidly increase until they reach the surface water level.

[60] Despite much faster wetting front movement within the $8.5 \mathrm{~mm}$ beach, compared to the $1.5 \mathrm{~mm}$ beach, the corresponding buildup of pore-air pressure is considerably lower: for the $8.5 \mathrm{~mm}$ beach the additional pressure head due to air reaches a magnitude of approximately $p /(\rho g)=$ $20 \mathrm{~mm}$, compared to $150 \mathrm{~mm}$ for the $1.5 \mathrm{~mm}$ beach. This behavior results from the easier air escape in the more permeable $8.5 \mathrm{~mm}$ beach.

[61] The beginning of the pressure buildup and the moment when the wetting front hits the groundwater can be detected more precisely from the local maxima of the second derivative of the pressure signal for the bottom pressure transducers, shown in Figure 17. The timing of the first peak coincides with the moment of the first response, i.e., the arrival of the air pressure "front," while the second peak shows the moment when the wetting front hits the groundwater. Figure 17 also shows the bore arrival time as a vertical line, confirming that in the $8.5 \mathrm{~mm}$ beach the pore-air pressure buildup starts somewhat before the bore arrival.

[62] Figure 18 shows the comparison of the shoreline propagation along the beach with the corresponding propagation of the pore-air pressure front for experiments of the 1.5 and $8.5 \mathrm{~mm}$ beaches. The shoreline and the pressure 

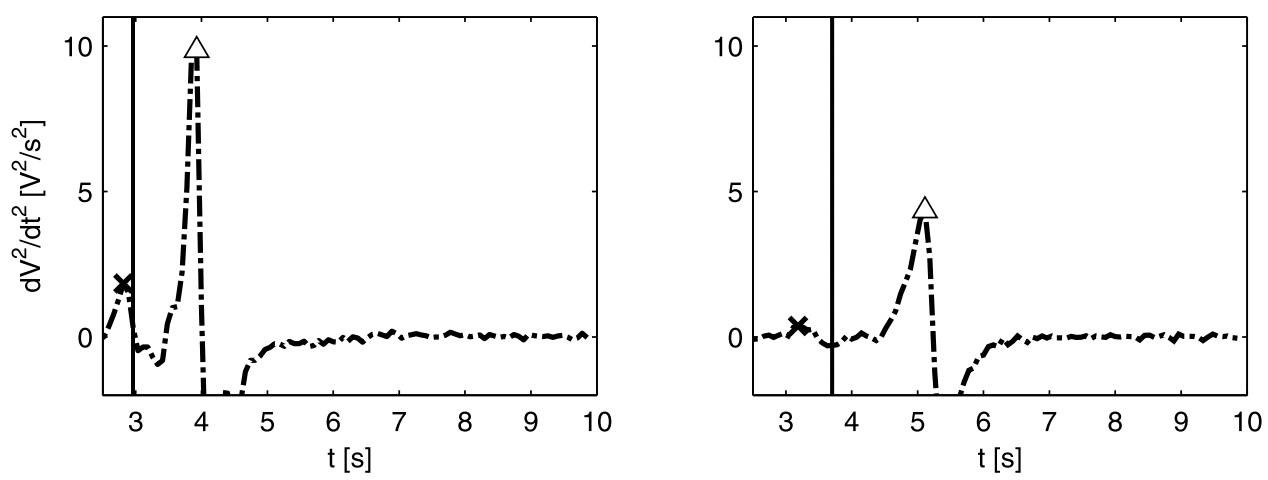

Figure 17. The second derivative of the pressure signal for the bottom transducer, with the cross denoting the initial pressure change due to air, the triangle denoting the wetting front arrival at the water table, and the vertical line denoting bore arrival at $x=1980$ and $2780 \mathrm{~mm}$ for the $8.5 \mathrm{~mm}$ beach with the $600 \mathrm{~mm}$ reservoir depth (R60PER085).

front are moving at similar speeds, with the pressure front slightly ahead in time.

\section{Vertical Hydraulic Gradients}

[63] Vertical hydraulic gradients indicate the driving force governing the rates of infiltration/exfiltration and thus the water exchange between the swash and the subsurface flow. In simulation models of swash [e.g., Clarke et al., 2004; van Gent, 1994] infiltration rates are often calculated by assuming a gradient of 1 . With the experimental data presented in sections 3 and 4 it is possible to estimate the hydraulic gradients and hence test this assumption. Evaluation of vertical hydraulic gradient has to consider the build up of pore-air pressure within the unsaturated region. Assuming negligible capillary head at the wetting front, the hydraulic gradient is expressed as

$$
I=\frac{\rho g h+\rho g\left(z_{b}-z_{f}\right)-p}{\rho g\left(z_{b}-z_{f}\right)},
$$

where $h$ is the flow depth at the beach face, $z_{f}$ denotes the level of the wetting front, $z_{b}$ is the level of the bed surface, $\rho$ denotes density of water, $g$ is the gravitational acceleration, and $p$ is the pore-air pressure below the wetting front in the unsaturated region of the beach, relative to atmospheric pressure.

[64] Another way of evaluating hydraulic gradients is to use the Forchheimer coefficients determined on the separate rig for the steady state flow (section 2.2) together with the infiltration rates calculated from the wetting front measurements.

[65] Figure 19 presents time series of the hydraulic gradient at several cross-shore locations for the two beaches. Pluses correspond to the values obtained from equation (4) and circles correspond to the values obtained from the Forchheimer equation. Values for the gradient are only determined for times corresponding to when the wetting front is moving. Positive gradients are associated with infiltration. The results obtained using two independent methods for evaluating hydraulic gradients show encouraging similarity.

[66] Hydraulic gradients in the $1.5 \mathrm{~mm}$ beach are much less than 1 at all locations, and for the lowest location $x=$ $1180 \mathrm{~mm}$ they even become negative, indicating exfiltration. For this location the estimate based on the Forchheimer equation is omitted because the tracking of the upward movement of the wetting front from the image analysis was not sufficiently accurate for evaluation of gradients. Exfiltration occurring at the lower end of the $1.5 \mathrm{~mm}$ beach was first inferred from the pressure results shown in section 4. Looking back at the subsurface profiles for the $1.5 \mathrm{~mm}$ beach shown in Figure 11, we notice that the wetting front tends to be shallower at the lower end of the beach, although infiltration starts earlier and is driven by larger surface depths than further up the slope. This means that the wetting front is at some point in time pushed up toward the beach surface, hence exfiltration is taking place.

[67] For the $8.5 \mathrm{~mm}$ beach the values for the hydraulic gradients are always positive, i.e., infiltration occurs within the $8.5 \mathrm{~mm}$ beach across the swash zone for both uprush and
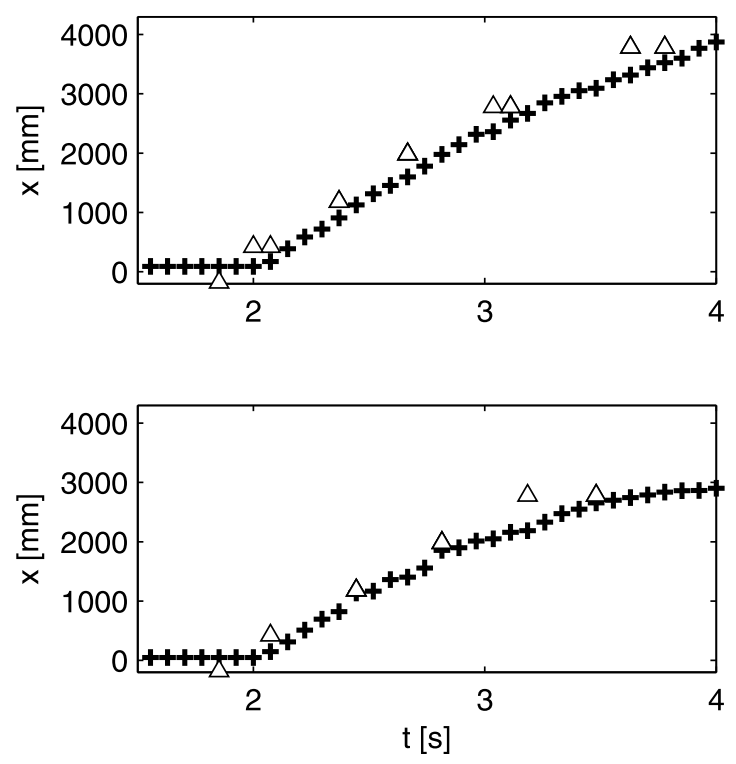

Figure 18. Time series of the pressure front (triangles) and the shoreline position (pluses) during uprush for the (top) $1.5 \mathrm{~mm}$ beach of experiment R60PER015 and (bottom) $8.5 \mathrm{~mm}$ beach with the $600 \mathrm{~mm}$ reservoir depth of experiment R60PER085. Note that most cross-shore locations have a number of transducers and as a result markers denoting the arrival of the pressure front overlap each other. 

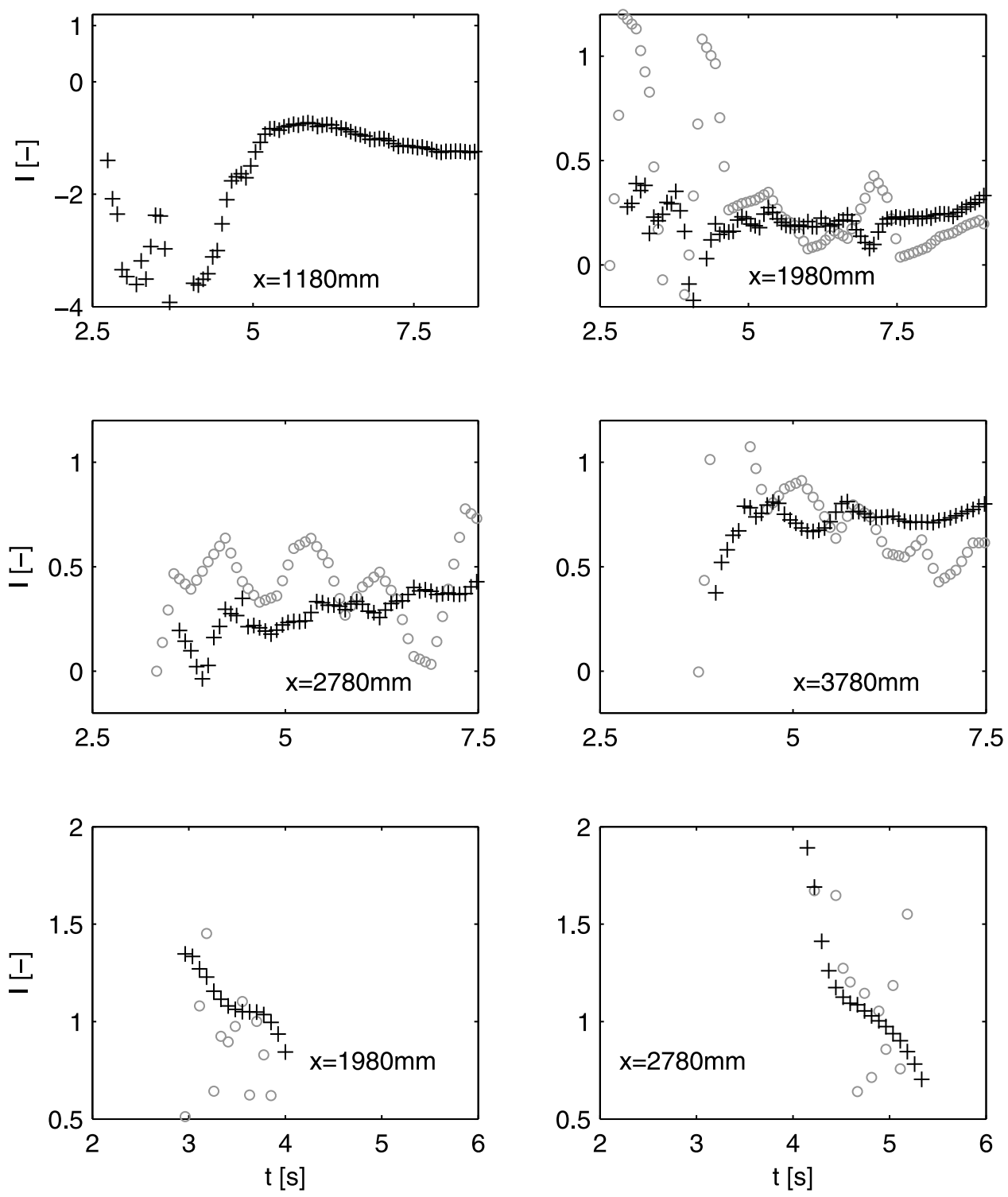

Figure 19. Time series of hydraulic gradient (top and middle) at $x=1180,1980,2780$, and $3780 \mathrm{~mm}$ for the $1.5 \mathrm{~mm}$ beach (R60PER015) and (bottom) at $x=1980$ and $2780 \mathrm{~mm}$ for the $8.5 \mathrm{~mm}$ beach with the $600 \mathrm{~mm}$ reservoir depth (R60PER085) based on equation (4) (pluses) and the Forchheimer equation (circles).

backwash phases of the swash cycle. For a good part of the swash cycle the gradients are significantly higher than one and also more than twice the magnitude of the gradients within the $1.5 \mathrm{~mm}$ beach. The difference between the two beaches results from the greater effect of air encapsulation in the $1.5 \mathrm{~mm}$ beach, which significantly reduces vertical hydraulic gradients.

\section{Groundwater Response to Infiltration Within $8.5 \mathrm{~mm}$ Beach}

[68] In the $1.5 \mathrm{~mm}$ beach the influence of the surface flow on the ambient groundwater during the swash cycle was negligible, because the majority of infiltrated water remained within the top layer of the beach and did not reach the groundwater level by the end of the swash cycle (Figure 11). In the $8.5 \mathrm{~mm}$ beach, however, infiltration was rapid, and the wetting front reached the groundwater level across majority of the swash zone during the uprush. The resulting response of ambient groundwater is discussed in this section.

[69] Groundwater levels were evaluated from the pressure measurements recorded by the transducers situated below the initial groundwater level $\left(P_{i 0}\right)$. During a short period between the time of bore arrival at a particular location and the time when the wetting front reaches the groundwater, the pressure measurements are dominated by the pore-air pressure buildup, which is bigger than the change in groundwater level. After this short period it is possible to select times when the pressures recorded by the lowest transducers are no longer affected by the increase in pore-air pressure, and the measured pressure head directly shows the groundwater level (if the beach is unconfined), or shows the hydraulic head (if the beach is confined).

[70] Figure 20 shows profiles of surface water, groundwater and the wetting front at two stages of the swash cycle, 

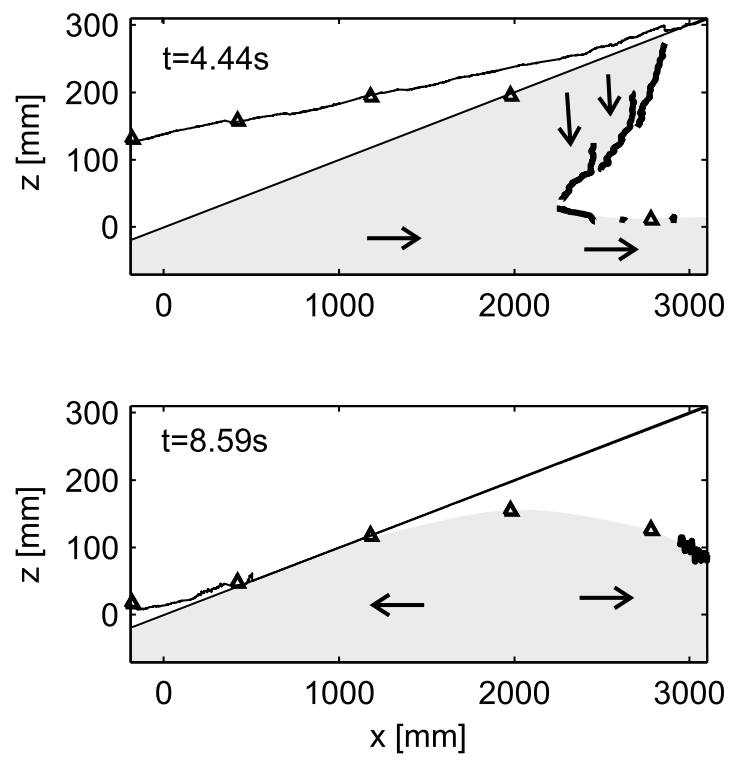

Figure 20. Surface and subsurface profiles at two selected times for the $8.5 \mathrm{~mm}$ beach with the $600 \mathrm{~mm}$ reservoir depth (R60PER085). Thin black line indicates swash and thick black line indicates the wetting front or groundwater level. The point measurements of the pressure transducers are indicated by triangles. The saturated region within the beach is shaded.

overlayed by a sketch of the inferred direction of groundwater flow.

[71] Figure 20 (top) shows the late uprush $(t=4.44 \mathrm{~s})$. In the lower part of the beach the wetting front has merged with the groundwater (propagation of the wetting front prior to this moment was shown in Figure 11). Further up the slope the wetting front is moving toward the groundwater. Groundwater levels below the wetting front are slightly raised, due to infiltration at the lowest end of the beach generating horizontal groundwater movement. The overall shape of the groundwater profile is similar to those shown by Austin and Masselink [2006], who inferred a dual pathway infiltration model from field measurements of pressure in a $6 \mathrm{~mm}$ gravel beach. The only difference is that in our experiments the wetting front was directly recorded, making it possible to measure its typical convex shape and to locate the point where the wetting front meets the groundwater level and the subsurface flow direction changes from nearly vertical infiltration to nearly horizontal groundwater flow.

[72] Figure 20 (bottom) shows the late backwash $(t=$ $8.59 \mathrm{~s}$ ). The surface flow has retreated, forming a seepage face. Groundwater flow diverges: at the lower end of the beach the groundwater drains in the seaward direction (both through the seepage face and the submerged lowest end of the beach face), whereas further into the beach it flows in the shoreward direction.

[73] Figure 20 shows consistency in the experimental results. Across the majority of the fully saturated part of the beach the hydraulic heads within the beach evaluated from measured pressures $\left(P_{i 0}\right)$ show excellent agreement with the LIF surface level measurements. In the uprush $(t=4.44 \mathrm{~s})$ there is a single location $(x \sim 2000 \mathrm{~mm})$ where the beach is saturated, but the groundwater hydraulic head is not at the surface water level; instead it is approximately at the beach face. The difference between the surface water level and the groundwater hydraulic head indicates downward movement of infiltrating water. This observation point is close to the unconfined part of the beach, so the nearly vertical movement which originated from the downward moving wetting front is still significant. Seaward of this point the agreement between the pressure and surface level measurements confirms that the groundwater movement along this part of the beach is nearly horizontal. Further shoreward the agreement between the groundwater levels evaluated from pressure measurements and the wetting front recorded using image analysis is very good in both uprush and backwash.

[74] For the purpose of modeling groundwater in the swash zone it is useful to define the position of the most shoreward, fully saturated (confined) cross section. This cross section, which we call the saturation boundary marks the most shoreward location where groundwater is directly connected to the surface water (i.e., swash lens). During uprush the saturation boundary is the cross section where the wetting front has just reached the groundwater level; during backwash the saturation boundary usually coincides with the so-called exit point, i.e., the point where the groundwater table intersects with the beach face.

[75] Figure 21 shows the position of the saturation boundary and the shoreline position throughout the swash
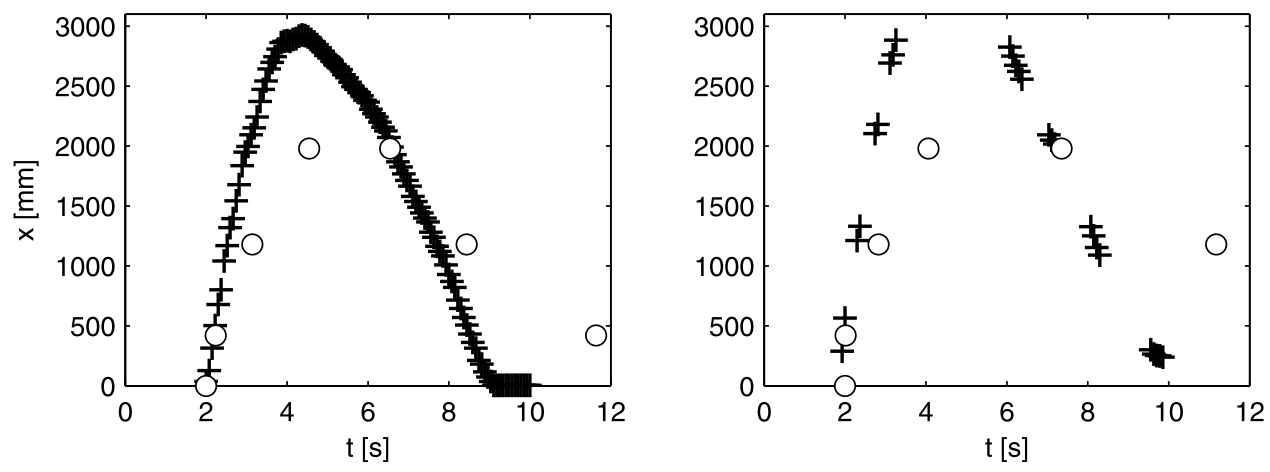

Figure 21. Time series of shoreline position (pluses) and saturation boundary (circles) for the $8.5 \mathrm{~mm}$ beach with the (left) 600 and (right) $700 \mathrm{~mm}$ reservoir depth of experiment R60PER085 and R70PER085, respectively. 
cycle, for the two $8.5 \mathrm{~mm}$ beach experiments (the 600 and $700 \mathrm{~mm}$ reservoir depths). During uprush the saturation boundary moves shoreward, lagging slightly behind the shoreline position. After flow reversal, in the early stages of the backwash, infiltration continues, so the saturation boundary can move slightly further shoreward. However, by the time the retreating shoreline has reached the saturation boundary, the beach begins to drain: this occurs at approximately $7 \mathrm{~s}$ for the $600 \mathrm{~mm}$ reservoir depth and at approximately $7.5 \mathrm{~s}$ for the $700 \mathrm{~mm}$ reservoir depth. A seepage face develops between the shoreline and the exit point, which gradually follows the bore tip in the seaward direction.

[76] The fact that shoreline position and saturation boundary in Figure 21 are not coincident shows that groundwater flow and surface flow are not fully coupled (i.e., they do not share a common boundary along the beach face) at any stage of the swash cycle. This finding is not limited to highly permeable beaches. On the contrary, the decoupling is even more pronounced for less permeable beaches: for the $1.5 \mathrm{~mm}$ beach the saturation boundary remained very close to the initial shoreline position throughout the swash cycle.

\section{Conclusion}

[77] New laboratory experiments have yielded detailed measurements of subsurface hydrodynamics resulting from bore-driven swash on permeable immobile beaches. The experiments were conducted on two beaches made of different size sediment $(1.5$ and $8.5 \mathrm{~mm})$ with the same slope of 1:10. The following conclusions are drawn from the study:

[78] 1. Beach grain size determines beach permeability and surface roughness and has a major effect on the surfacesubsurface exchange and subsurface hydrodynamics.

[79] 2. The wetting front pushes air within the unsaturated zone of the beach. In the presence of the ambient groundwater the air becomes entrapped, and the pore-air pressure increases hence reducing infiltration rates.

[80] 3. The pressure buildup results from the imbalance between the downward infiltration of water and the shoreward movement of air.

[81] 4. In the $1.5 \mathrm{~mm}$ beach, air encapsulation played a major role in the water exchange between the surface and subsurface flow. The interstitial air pressure buildup decreased infiltration rate to such an extent that during the swash cycle the wetting front did not reach the top of the capillary fringe across the majority of the beach. Furthermore, at the lower end of the beach entrapped air reversed the direction of the wetting front and caused exfiltration. In the same region some amount of air managed to escape through preferential pathways straight into the surface flow, during uprush and a good part of the backwash.

[82] 5. Air entrapment played only a minor role in the $8.5 \mathrm{~mm}$ beach. The beach rapidly became fully saturated over the majority of the shoreline excursion.

[83] 6. By the time of maximum runup, approximately $20 \%$ and $45 \%$ of the incident water volume infiltrated the $1.5 \mathrm{~mm}$ beach and $8.5 \mathrm{~mm}$ beach, respectively. Infiltration rates across the swash zone and for the entire swash cycle differed by an order of magnitude between the two beaches,
Table A1. Pressure Transducer Locations for the 1.5 and $8.5 \mathrm{~mm}$ Beaches $^{\mathrm{a}}$

\begin{tabular}{|c|c|c|c|}
\hline Transducer & $x(\mathrm{~mm})$ & $z(\mathrm{~mm})$ & $r m s(\mathrm{~mm})$ \\
\hline \multicolumn{4}{|c|}{$1.5 \mathrm{~mm}$ Beach } \\
\hline$P_{10}$ & -180 & -66.2 & 0.93 \\
\hline$P_{20}$ & 420 & -69.8 & 0.71 \\
\hline$P_{21}$ & 420 & -15.0 & 1.92 \\
\hline$P_{30}$ & 1180 & -65.9 & 1.28 \\
\hline$P_{31}$ & 1180 & 26.0 & 1.03 \\
\hline$P_{40}$ & 1980 & -64.9 & 1.58 \\
\hline$P_{41}$ & 1980 & 123.0 & 1.34 \\
\hline$P_{42}$ & 1980 & 61.0 & 1.14 \\
\hline$P_{50}$ & 2780 & -71.8 & 1.92 \\
\hline$P_{51}$ & 2780 & 218.5 & 1.44 \\
\hline$P_{52}$ & 2780 & 195.0 & 0.62 \\
\hline$P_{53}$ & 2780 & 136.5 & 0.85 \\
\hline$P_{60}$ & 3780 & -70.2 & 0.73 \\
\hline$P_{61}$ & 3780 & 321.5 & 1.15 \\
\hline$P_{62}$ & 3780 & 290.0 & 0.55 \\
\hline$P_{63}$ & 3780 & 218.0 & 1.79 \\
\hline \multicolumn{4}{|c|}{$8.5 \mathrm{~mm}$ Beach } \\
\hline$P_{10}$ & -180 & -68.1 & 0.94 \\
\hline$P_{20}$ & 420 & -64.8 & 0.73 \\
\hline$P_{30}$ & 1180 & -67.8 & 0.82 \\
\hline$P_{31}$ & 1180 & 54.0 & 2.46 \\
\hline$P_{32}$ & 1180 & 36.0 & 2.59 \\
\hline$P_{40}$ & 1980 & -65.1 & 0.79 \\
\hline$P_{41}$ & 1980 & 138.0 & 2.24 \\
\hline$P_{42}$ & 1980 & 115.0 & 1.28 \\
\hline$P_{50}$ & 2780 & -65.2 & 1.17 \\
\hline$P_{51}$ & 2780 & 202.0 & 1.23 \\
\hline$P_{52}$ & 2780 & 199.0 & 0.62 \\
\hline
\end{tabular}

${ }^{a}$ Setup illustrated in Figure 5. The rows denoted in bold indicate the bottom pressure transducers. The root mean square error (rms) is given in $\mathrm{mm}$ and is averaged over the swash cycle in the main experiments, i.e., R60PER015 and R60PER 100 .

with average infiltration rates of approximately $5 \mathrm{~mm} / \mathrm{s}$ for the $1.5 \mathrm{~mm}$ sediment and approximately $50 \mathrm{~mm} / \mathrm{s}$ for the $8.5 \mathrm{~mm}$ sediment.

[84] 7. Due to pore-air pressure buildup, vertical hydraulic gradients in the $1.5 \mathrm{~mm}$ beach were relatively small, of the order of 0.5 , and even negative at the lower end of the beach. In the $8.5 \mathrm{~mm}$ beach the vertical gradients were considerably larger than unity for at least half of the swash cycle.

[85] 8. The subsurface flow was distinctly different for the two beaches. In the $1.5 \mathrm{~mm}$ beach the majority of infiltrated water remained within the top layer of the beach and did not reach the groundwater level during the entire swash event. In the $8.5 \mathrm{~mm}$ beach infiltration was rapid with the wetting front reaching the groundwater level at most cross-shore locations during the uprush.

[86] 9. The results illustrate the complexity of subsurface flow behavior within coarse-grained beaches in response to bore-induced swash. They show that for coarse-grained beaches we have to consider both the infiltration into the unsaturated region above the groundwater level and the movement of the ambient groundwater itself. Furthermore, both wetting front propagation and groundwater movement are affected by air encapsulated within the unsaturated region located below the wetting front and above the groundwater level.

[87] 10. These findings have important implications for modeling swash zone processes: (1) air encapsulation has to 
Table B1. Wetting Front Measurements ${ }^{\mathrm{a}}$

\begin{tabular}{lccc}
\hline Experiment & $x(\mathrm{~mm})$ & Camera View $x(\mathrm{~mm})$ & Camera View $z(\mathrm{~mm})$ \\
\hline & & 1.5 mm Beach & \\
WET00 & 1163 & 281.28 & 210.96 \\
WET01 & 1463 & 282.40 & 211.80 \\
WET02 & 1763 & 278.72 & 209.04 \\
WET03 & 2063 & 280.96 & 210.72 \\
WET04 & 2378 & 211.80 & 282.40 \\
WET05 & 2608 & 210.00 & 280.00 \\
WET06 & 2838 & 210.48 & 280.64 \\
WET07 & 3068 & 234.96 & 313.28 \\
WET08 & 3298 & 235.08 & 313.44 \\
WET09 & 3588 & 236.04 & 314.72 \\
WET10 & 3838 & 309.12 & 231.84 \\
WET11 & 4118 & 247.52 & 185.64 \\
& & & \\
WET01 & 1463 & 8.5 mm Beach & 224.88 \\
WET02 & 1763 & 299.84 & 224.16 \\
WET03 & 2063 & 298.88 & 224.64 \\
WET04 & 2378 & 299.52 & 304.00 \\
WET05 & 2608 & 228.00 & 303.68 \\
WET06 & 2838 & 227.76 & 299.68 \\
WET07 & 3068 & 224.76 & 296.32 \\
\hline
\end{tabular}

${ }^{\mathrm{a}}$ The $x$ locations of the image center and physical dimensions of camera views in $x$ and $z$ direction for the 1.5 (R60PER015) and 8.5 (R60PER100) $\mathrm{mm}$ beaches.

be included in the models and (2) surface flow and groundwater flow are not fully coupled, i.e., their boundaries at the beach face do not coincide throughout the swash cycle.

[88] 11. The experimental results form a comprehensive data set which can be used to validate numerical models of swash on permeable, immobile slopes. The data are available on request to the authors.

\section{Appendix A}

[89] Table A1 presents the locations of pressure transducers.

\section{Appendix B}

[90] Table B1 presents the locations of wetting front images.

[91] Acknowledgments. This work was part of a research project funded by the UK's EPSRC (grant EP/E011330/1). K.S.'s Ph.D. study was funded by the University of Aberdeen. The authors would like to thank University of Aberdeen Fluids Laboratory technicians Alan Styles and Grant Cordiner for their assistance with the experiments.

\section{References}

Austin, M. J., and G. Masselink (2006), Swash-groundwater interaction on a steep gravel beach, Cont. Shelf Res., 26, 2503-2519.

Bagnold, R. A. (1940), Beach formation by waves: Some model experiments in a wave tank, J. Inst. Civ. Eng., 15, 27-52.

Butt, T., P. Russell, and I. L. Turner (2001), The influence of swash infiltration-exfiltration on beach sediment transport: Onshore or offshore? Coastal Eng., 42, 35-52.

Clarke, S., N. Dodd, and J. Damgaard (2004), Modelling flow in and above a porous beach, J. Waterw. Harbors Coastal Eng. Div. Am. Soc. Civ. Eng., 130, 223-233.

Conley, D. C., and D. L. Inman (1994), Ventilated oscillatory boundary layers, J. Fluid Mech., 273, 261-284.

Constantz, J., W. N. Herkelrath, and F. Murphy (1988), Air encapsulation during infiltration, Soil Sci. Soc. Am. J., 52, 10-16.

Fand, R. M., B. Y. K. Kim, A. C. C. Lam, and R. T. Phan (1987), Resistance to the flow of fluids through simple and complex porous media whose matrices are composed of randomly packed spheres, J. Fluids. Eng., 109, 268-274.

Faybishenko, B. A. (1995), Hydraulic behaviour of quasi-saturated soils in the presence of entrapped air: Laboratory experiments, Water Resour. Res., 31, 2421-2435.

Horn, D. P. (2002), Beach groundwater dynamics, Geomorphology, 48, $121-146$.

Horn, D. P. (2006), Measurements and modelling of beach groundwater flow in the swash-zone: A review, Cont. Shelf Res., 26, 622-652.

Horn, D. P., and L. Li (2006), Measurement and modelling of gravel beach groundwater response to wave run-up: Effects on beach profile changes, J. Coastal Res., 22, 1241-1249.

Lara, J. L., I. J. Losada, and P. L. F. Liu (2006), Breaking waves over a mild gravel slope: Experimental and numerical analysis, J. Geophys. Res., 111, C11019, doi:10.1029/2005JC003374.

Masselink, G., and L. Li (2001), The role of swash infiltration in determining the beach face gradient: A numerical study, Mar. Geol., 176, 139-156.

Masselink, G., P. Russell, C. Blenkinsopp, and I. Turner (2010), Swash zone sediment transport, step dynamics and morphological response on a gravel beach, Mar. Geol., 274, 50-68.

Nielsen, P. (1992), Coastal Bottom Boundary Layers and Sediment Transport, Adv. Ser. Ocean Eng., vol. 4, World Scientific, Singapore.

Nielsen, P. (1997), Coastal groundwater dynamics, paper presented at Coastal Dynamics '97, Am. Soc. of Civ. Eng., Plymouth, Mass.

O'Donoghue, T., L. J. Hondebrink, and D. Pokrajac (2010), Laboratory and numerical study of dambreak-generated swash on impermeable slopes, Coastal Eng., 57, 513-530.

Puleo, J. A., and K. T. Holland (2001), Estimating swash zone friction coefficients on a sandy beach, Coastal Eng., 43, 25-40.

Turner, I. L. (1993), The total water content of sandy beaches, J. Coastal Res., 15, 11-26.

Turner, I. L., and G. Masselink (1998), Swash infiltration-exfiltration and sediment transport, J. Geophys. Res., 103, 30,813-30,824.

van Gent, M. R. A. (1994), The modelling of wave action on and in coastal structures, Coastal Eng., 22, 311-339.

G. A. Kikkert, Department of Civil and Environmental Engineering, Hong Kong University of Science and Technology, Room 3575, Main Academic Building, Clear Water Bay, Kowloon, Hong Kong.

T. O'Donoghue, D. Pokrajac, and K. Steenhauer, School of Engineering, University of Aberdeen, Fraser Noble Building, Kings College, Aberdeen, AB24 3UE, UK. (k.steenhauer@abdn.ac.uk) 